\title{
In silico Study of Iron, Zinc and Copper Binding Proteins of Pseudomonas syringae pv. lapsa: Emphasis on Secreted Metalloproteins
}

Ankita Sharma, Dixit Sharma and Shailender K. Verma*t

Centre for Computational Biology and Bioinformatics, School of Life Sciences, Central University of Himachal Pradesh, Kangra, India

OPEN ACCESS

Edited by:

Manuel Simões,

Universidade do Porto, Portugal

Reviewed by:

Romé Voulhoux

UMR7255 Laboratoire d'Ingénierie des Systèmes Macromoléculaires,

France

Hans-Georg Koch

Albert-Ludwigs-Universität Freiburg,

Germany

${ }^{*}$ Correspondence:

Shailender K. Verma

skverma@cuhimachal.ac.in; skverma.cuhl@nic.in

${ }^{\dagger}$ Present address:

Shailender K. Verma,

Department of Biological Chemistry, John Innes Centre, Norwich,

United Kingdom

Specialty section:

This article was submitted to Microbial Physiology and Metabolism,

a section of the journal

Frontiers in Microbiology

Received: 16 April 2018

Accepted: 23 July 2018

Published: 21 August 2018

Citation:

Sharma A, Sharma D and Verma SK

(2018) In silico Study of Iron, Zinc and Copper Binding Proteins of Pseudomonas syringae pv. lapsa: Emphasis on Secreted Metalloproteins.

Front. Microbiol. 9:1838. doi: 10.3389/fmicb.2018.01838
The phytopathogenic bacteria, Pseudomonas syringae pv. lapsa (P. syringae pv. lapsa) infects the staple food crop wheat. Metalloproteins play important roles in plant-pathogen interactions. Hence, the present work is aimed to predict and analyze the iron $(\mathrm{Fe})$, zinc $(\mathrm{Zn})$, and copper $(\mathrm{Cu})$ binding proteins of $P$. syringae pv. lapsa which help in its growth, adaptation, survival and pathogenicity. A total of $232 \mathrm{Fe}, 307 \mathrm{Zn}$, and $38 \mathrm{Cu}$-binding proteins have been identified. The functional annotation, subcellular localization and gene ontology enriched network analysis revealed their role in wide range of biological activities of the phytopathogen. Among the identified metalloproteins, a total of $29 \mathrm{Fe}$-binding, $31 \mathrm{Zn}$-binding, and 5 Cu-binding proteins were found to be secreted in nature. These putative secreted metalloproteins may perform diverse cellular and biological functions ranging from transport, response to oxidative stress, proteolysis, antimicrobial resistance, metabolic processes, protein folding and DNA repair. The observations obtained here may provide initial information required to draft new schemes to control microbial infections of staple food crops and will further help in developing sustainable agriculture.

Keywords: P. syringae pv. lapsa, metal binding proteins, plant-pathogen interaction, secreted metalloproteins, in silico

\section{INTRODUCTION}

Transition metals are essential micronutrients for all living forms principally due to their ability to couple with proteins to form metalloproteins (Bowman et al., 2016). Approximately one-third of all the studied proteins require at least one metal ion to carry out its function (Shi and Chance, 2011). The interactions between protein and bound prosthetic metal atom in metalloproteins help them to complete the diverse functions of catalysis, regulation and structure stabilization (Andreini et al., 2013; Zhang et al., 2016).

The first-row transition metals such as iron $(\mathrm{Fe})$, zinc $(\mathrm{Zn})$, and copper $(\mathrm{Cu})$ are vital for growth and proliferation of nearly all the organisms. Iron metal has incomplete "d" orbital which permits it to attain different oxidation states and redox chemistry (Cotton, 2000). As a result of this unique chemistry, iron act as cofactor for number of enzymes and has essential roles in oxygen metabolism, electron transport, tricarboxylic acid (TCA) cycle, lipid metabolism and peroxide detoxification (Krewulak and Vogel, 2008; Cornelis et al., 2011; Zhang, 2014; Ma et al., 2015). Zinc is one of the 
most abundant transition metal in the cell and plays important activity in structural stabilization and catalytic mechanisms of various proteins. Zinc containing proteins function in the broad range of cellular processes like storage, DNA replication, reactive oxygen species (ROS) detoxification, regulation of gene expression, carbohydrate oxidation and alcoholic fermentation (Murakami and Hirano, 2008; Maret, 2013; Ma et al., 2015). Copper is also an essential metal micronutrient for structural stabilization of proteins (Kaim and Rall, 1996) and for the catalysis of multiple redox activities of transport, denitrification and oxidative respiration (Cobine et al., 2006; Tavares et al., 2006; Festa and Thiele, 2012). Copper is also vital for various metabolic processes related to energy production, melanin biosynthesis and antioxidant defense (Kim et al., 2008).

Metals play key roles in various biochemical processes but are toxic in excess. It is also known that the concentration and availability of essential transition metals in the environment have significant roles in the plant-pathogen relationship. The competition between plant and phytopathogen for these essential micronutrients is a decisive factor for upshot, establishment and proliferation of infection (Fones and Preston, 2013). The phytopathogen invades the host cell and deregulates the host metal metabolism through nutrition alteration and genetic mutation which further raises the susceptibility for the infection (Fatima and Senthil-Kumar, 2015). In response, the host evolves the remedies that either block metal acquisition of the phytopathogen which restrict the availability of the nutrients or storm the phytopathogen with the higher concentration of metals (Hood and Skaar, 2012).

Pseudomonas syringae ( $P$. syringae) is a Gram-negative, aerobic, polar flagella bearing rod-shaped phytopathogenic bacteria. P. syringae encompasses 64 pathovars, which could infect a number of agriculturally important plants such as tomato, wheat, barley, pea and apple (Young, 2010). P. syringae pv. lapsa is an obligate pathogen of wheat (Triticum spp.). The infection of $P$. syringae pv. lapsa results in poor grain quality, yield reduction and economic loss (Kong et al., 2016). $P$. syringae accounts for approximately $5-50 \%$ of wheat yield loss, worldwide (Valencia-Botín and Cisneros-Opez, 2012). Wheat is a staple food for majority of the global population and mineral micronutrients play important role in its growth, development and various biochemical processes (Verma et al., 2017). The numerous attempts have been made to biofortify it for mineral micronutrients, such as iron and zinc (Verma et al., 2016a,b). The wheat plant and its bacterial pathogen compete for these micronutrients (Sharma et al., 2017). A number of virulence determinants which contribute in the pathogenesis of phytobacteria are extracellular polysaccharides, flagella, secreted proteins, phytohormones, phytotoxin, multidrug efflux pumps and detoxification enzymes (Ichinose et al., 2013). The metal homeostasis has also been illustrated as a key virulence factor for the phytobacterial pathogenicity (Bronstein et al., 2005; Taguchi et al., 2010; Fones and Preston, 2013).

The scarcity and excess of the essential metals must be synchronized to attain metal equilibrium in an organism (Chandrangsu et al., 2017). To gain insight into the metal homeostatic mechanisms of an organism the preliminary requirement is to unveil the complete facts and knowledge of the metalloproteins encoded by those organisms. Several experimental techniques like immobilized metal affinity chromatography and mass spectrometry, inductively coupled plasma atomic emission spectrometer, metal-affinity columns and shift assay, nuclear magnetic resonance spectroscopy and high throughput X-ray absorption spectroscopy are used for the prediction of metalloproteins (Shi et al., 2011; Lu et al., 2012). The major analytical challenge which hampers the prediction of metalloproteins using these techniques is to preserve the native structure of the metalloproteins during analysis. To study metal-protein interactions, use of conventional techniques are also limited because these require denaturation of the proteins which may result in disruption of weak ionic interactions of the metalloprotein bonds (Lothian et al., 2013). Further, the experimental approaches are very costly, time-consuming, require specialized equipments and skilful handling during sample preparation which limit their use to analyze the whole metalloproteome of an organism (Lubec and Afjehi-Sadat, 2007). Recent advances in the whole genome sequencing and annotation technologies have provided the access to the whole genome and proteome of different organisms. A number of bioinformatics tools and databases are also available to explore whole proteome for identification and analysis of metalloprotein motifs (Mallick et al., 2011; Andreini et al., 2013). The literature study directs us to hypothesize that $\mathrm{Fe}, \mathrm{Zn}$, and $\mathrm{Cu}$-binding proteins may have the significant impact on growth, development and virulence of P. syringae pv. lapsa. To understand role of metalloproteins and metal homeostasis mechanism of the selected phytopathogen, the primary requirement is to attain complete knowledge of all the $\mathrm{Fe}, \mathrm{Zn}$, and $\mathrm{Cu}$-binding proteins. Therefore, this study was aimed at proteome wide identification of metalloproteins of wheat-phytopathogen $P$. syringae pv. lapsa ATCC 10859 using a systematic in silico approach, in which multiple computational programs have been used in combination to maintain the prediction accuracy. Additionally, due to the importance of transition metals in co-regulation of secreted metalloproteins, we have also identified the secreted metalloproteins which may be involved in the virulence of the bacteria. In this comprehensive in silico report, we are providing the list of putative candidate metalloproteins which may be effective start-up data for experimental analysis and could be targeted to reduce the virulence of the pathogenic bacteria. Furthermore, this will also enhance our knowledge regarding phytobacterial virulence and metal homeostasis.

\section{MATERIALS AND METHODS}

\section{Retrieval of Proteome Dataset and Identification of Iron, Zinc, and Copper Binding Sequence Motifs}

We have retrieved the entire dataset of $\mathrm{Fe}, \mathrm{Zn}$, and $\mathrm{Cu}$-binding proteins available at MetalPDB (Andreini et al., 2013). MetalPDB is a database which provides the detailed insight into the interactions of metal-binding biological macromolecules and 
focused on minimal functional site prediction of metalloproteins. MetalPDB database contains the data regarding features of metalloproteins from PDB, Pfam, CATH and SCOP databases. To search the proteome against MetalPDB database we have retrieved the entire dataset of $\mathrm{Fe}, \mathrm{Zn}$, and $\mathrm{Cu}$-binding proteins available at MetalPDB. The whole proteome dataset of $P$. syringae pv. lapsa containing 4962 proteins, was retrieved from RefSeq National Center for Biotechnology Information (NCBI) ftp server $^{1}$ (Kong et al., 2016). All of the 4962 proteins were searched against $\mathrm{Fe}, \mathrm{Zn}$, and $\mathrm{Cu}$-binding proteins dataset of MetalPDB at expect value (e-value) 0.00001 . The protein sequences which showed homology equal to and below the cut-off $e$-value were selected for further analysis.

\section{Identification of Iron, Zinc, and Copper Binding Structural Motifs and Analysis of Metal Interactions}

The 3D structure modeling of selected proteins was carried out using Protein Homology/analogY Recognition Engine v 2.0 (Phyre2) computational program (Kelley et al., 2015). Phyre2 shape tertiary structure of proteins using HMM-HMM alignment based remote homology techniques. The high throughput modeled proteins above the threshold criteria of confidence $\geq 90 \%$ and query coverage $\geq 50 \%$ were selected for prediction of structural metal ion binding patterns. A fragment transformation method based server Metal Ion Binding site (MIB) (Lu et al., 2012) was used to scan the structural motifs for binding with metal ions $\mathrm{Fe}^{2+}, \mathrm{Fe}^{3+}, \mathrm{Zn}^{2+}, \mathrm{Cu}^{+}$, and $\mathrm{Cu}^{2+}$. In fragment transformation method the fragments of query proteins structurally align to the template of metal ion binding residues and alignment score was assigned to each residue of query protein on the basis of sequence and structure conservation evaluation, which is generated by BLOSUM62 substitution matrix and root mean square deviation of C-alpha carbons of structural local alignment. The predicted residues bind to metal ion are those which score above the assigned threshold alignment score. The overall accuracy of the MIB server is $94.6 \%$ with $60.5 \%$ true positive rate and $5 \%$ false positive rate. Ligplot ${ }^{+}$, (Laskowski and Swindells, 2011) a ligand-protein interaction visualization tool was used to visualize and analyze the protein-metal ions interactions. The protein structures carrying metal ions binding up to most effective interaction radii of $3.5 \AA$ were selected (Yamashita et al., 1990).

\section{Functional Annotation}

The functional classification of the selected metalloproteins was done by analyzing conserved domains, family and superfamily using tools, InterProScan (Jones et al., 2014), Pfam (Finn et al., 2016) and National Center for Biotechnology Information-Conserved Domain Database (NCBI-CDD) (Marchler-Bauer et al., 2015) at default parameters. InterProScan database consists of integrated "signatures" or "predicted models" from diverse databases which represent the protein domain, functional sites and families. InterProScan provides robust,

${ }^{1}$ ftp://ftp.ncbi.nlm.nih.gov/genomes/all/GCF/001/482/725/GCF_001482725.1_ ASM148272v1 java based architecture which allow the biologist to analyze large genome scale protein-functional classification. The Pfam protein families database perform multiple sequence alignment to construct hidden markov model profile which is used to annotate protein families. CDD have experimentally derived site annotations which include active sites, protein-protein interaction sites, chemical binding and complement. In CDD the alignment models of representative sequence fragments are generated according to domain boundaries as found in $3 \mathrm{D}$ structure of the protein. Further, these alignments annotate the conserved features and model the structurally conserved cores of domain families. The putative $\mathrm{Fe}, \mathrm{Zn}$, and $\mathrm{Cu}$-binding proteins were further classified broadly and clustered on the basis of illustration of identified functional domains for their probable biological roles using MEGA6 (Tamura et al., 2013) and BioEdit (Hall, 1999). The clustergram was visualized by EvolView (Zhang et al., 2012) program.

\section{Subcellular Localization}

The subcellular localization of selected metalloproteins was done by CELLO (Yu et al., 2004), PSORTb v 3.0.2 (Yu et al., 2010) and Gneg-mPLoc (Shen and Chou, 2010). PSORTb program uses six modules each of having different module examining specific localization sites. By uniting the predictions from all the modules a Bayesian network is created which is used to predict the final localization of proteins on the basis of performance accuracies of each module. CELLO tool utilizes multilayered support vector machine classifiers to predict subcellular localization of Gramnegative bacteria. These multiple features vectors are based on multiple n-peptide compositions. Gneg-mPLoc server utilizes K-nearest neighbor algorithm to cluster the Swiss-Prot proteins with experimentally annotated subcellular localization on the basis of their amino acid properties and Gene Ontology (GO) terms for the prediction of subcellular localization of Gramnegative bacteria. The overall accuracy of CELLO, PSORTb and jackknife success rate of Gneg-mPLoc servers for prediction of subcellular localization of Gram-negative bacterial protein is 89 , 98.3, and $85.5 \%$ respectively. In case of discrepancy between the results obtained from different servers, the consensus of results from two or more than two programs were considered for assigning precise subcellular locations.

\section{Building of Grouped GO Biological Functionally Annotated Network of Predicted Iron, Zinc, and Copper Binding Proteins}

The GO biological function annotations (Ashburner et al., 2000) of all the predicted $\mathrm{Fe}, \mathrm{Zn}$, and $\mathrm{Cu}$ - binding proteins were done using ClueGO v2.3.3 (Bindea et al., 2009). ClueGO v2.3.3 is a Cytoscape v3.5.1 (Shannon et al., 2003) plug-in which was used to construct, visualize and analyze the GO enriched network. The GO biological process (BP) in the ClueGO program was represented by the node and the contacts between the GO BP terms on the basis of the overlap of their genes association, indicated by the edge. The kappa score (Huang et al., 2007) was used for the functional grouping of the GO terms and 


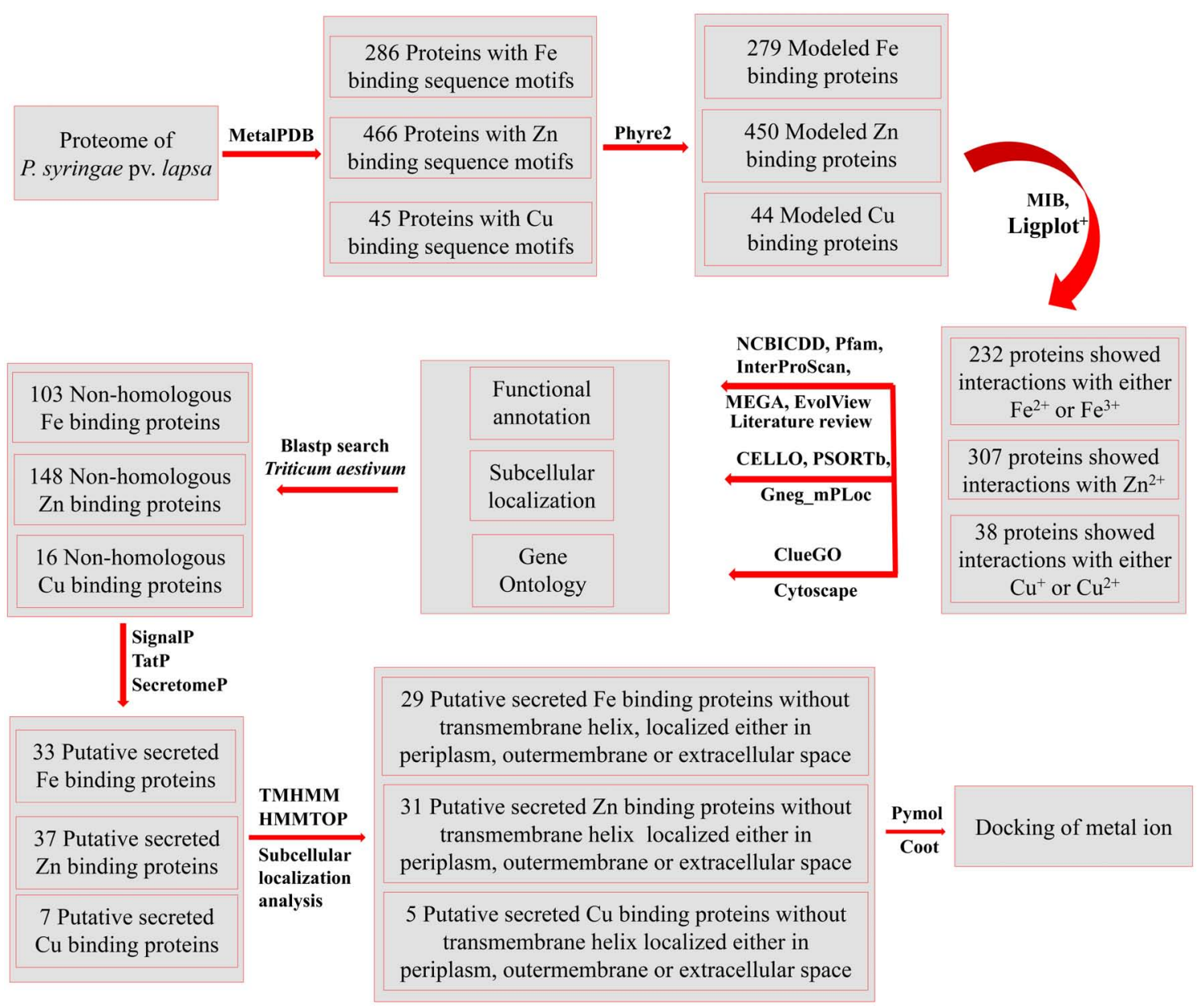

FIGURE 1 | The overall methodology of the present study. The whole proteome of $P$. syringae pv. lapsa was analyzed for identification of metal (Fe, Zn, and $\mathrm{Cu}$ ) binding sequence motifs using dataset of MetalPDB (Andreini et al., 2013) at e-value of 0.00001 . The high throughout modeling of selected proteins was done by Phyre2 (Kelley et al., 2015) and selected models were analyzed for metal ion binding structural motifs using MIB (Lu et al., 2012) and Ligplot ${ }^{+}$(Laskowski and Swindells, 2011). The functional annotation was done by InterProScan (Jones et al., 2014), Pfam (Finn et al., 2016), and NCBI-CDD (Marchler-Bauer et al., 2015). Clustering of the proteins were done by MEGA6 (Tamura et al., 2013) and EvolView (Zhang et al., 2012). The consensus of bioinformatics server CELLO (Yu et al., 2004), PSORTb (Yu et al., 2010), and Gneg-mPLoc (Shen and Chou, 2010) was used for subcellular localization of predicted metalloproteins. The Gene Ontology based biological function annotation networks were constructed by ClueGO (Bindea et al., 2009) and visualized by Cytoscape (Shannon et al., 2003). Blastp (Altschul et al., 1990) search was done against host proteome (Triticum aestivum) to identify non-homologous Fe, Zn, and Cu-binding proteins. Further, the putative secreted metal binding proteins were predicted by using SignalP (Petersen et al., 2011) TatP (Bendtsen et al., 2005) and SecretomeP (Bendtsen et al., 2004a) databases. The transmembrane analysis was done by TMHMM (Krogh et al., 2001) and HMMTOP (Tusnady and Simon, 2001) web servers. PyMol (DeLano, 2002) and Coot (Emsley and Cowtan, 2004) server were used for manual docking of metal ions and visualization of interactions.

their enrichment significance was represented by the size of the nodes.

\section{Homology Search With Host Proteome and Identification of Secreted Proteins}

The identified metalloproteins were searched against the host proteome (Triticum aestivum) using BLASTp (Basic Local Alignment Search Tool) (Altschul et al., 1990) at $e$-value 0.00001 . The non-homologous proteins with $e$-value score more than 0.00001 were shortlisted. The selected proteins were further screened for Sec and Tat-dependent secretory pathways using SignalP 4.1 (Petersen et al., 2011) and TatP 1.0 server (Bendtsen et al., 2005) respectively. SignalP program is based on the combination of several artificial neural networks and predicts the signal peptide and its cleavage site with $87 \%$ accuracy (Bendtsen et al., 2004b). TatP server was used to screen Tat-motif, which is based on a combination of two artificial neural networks and predict the twin-arginine signal peptide and its cleavage site with 91\% accuracy. The proteins with signal peptide were considered as Sec-dependent classical secreted proteins and proteins with Tat motif were considered as Tat-dependent secreted proteins. The proteins without signal peptides may secrete in an independent manner (non-classically secreted proteins) (Muesch et al., 1990) therefore, remaining proteins were examined by SecretomeP 2.0 (Bendtsen et al., 2004a) SecretomeP server uses artificial 


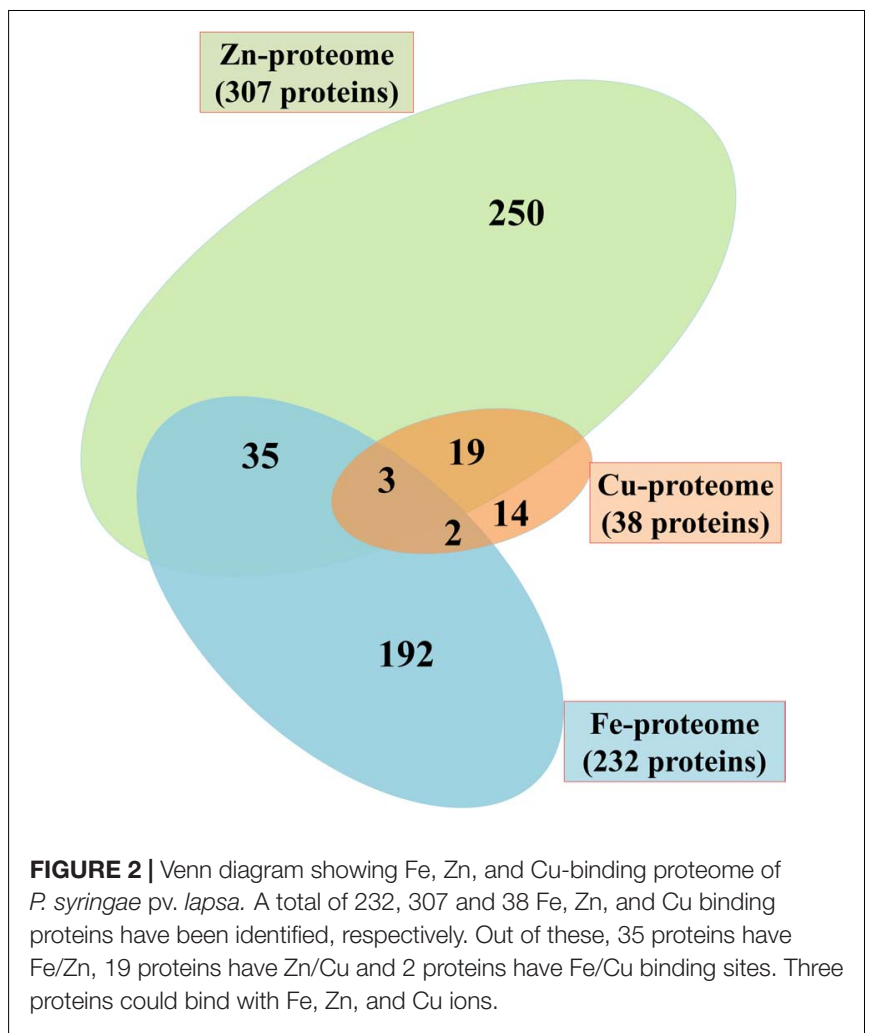

neural network architecture to predict non-classical secreted proteins which are based on sequence derived-protein features (amino acid composition, transmembrane helixes, gravy, protein disorder, secondary structure and instability index). The sensitivity of SecretomeP is $40 \%$ and is based on threefold cross-validation and calculations of the correlation coefficient of the combinations of proteins features yielding best performance. The proteins with sec-score $\geq 0.5$ were considered as non-classical secreted proteins. Further, the mature classically secreted proteins, Tat-dependent secreted proteins and non-classically secreted proteins were analyzed for the presence of hydrophobic regions (transmembrane alpha helix). This is because hydrophobic regions act as stop transfer signal and anchor the proteins in the innermembrane. The transmembrane alpha helix prediction was done by HMM-based Transmembrane Hidden Markov Model (TMHMM v 2.0) (Krogh et al., 2001) and Hidden Markov Model for topology prediction (HMMTOP) (Tusnady and Simon, 2001) having accuracy is 79 and $78 \%$ respectively. These shortlisted proteins also checked for their subcellular localization which is described in the previous section. The proteins without membrane anchor transmembrane helix and found to be localized either in periplasm, outermembrane or extracellular region were selected. These selected proteins which are either secreted by Sec-dependent, Tat-dependent and non-classical secretory pathways, having absence of transmembrane helix and localized either to periplasm, outermembrane or extracellular space were categorized as secreted metalloproteins.

\section{Molecular Docking of Secreted Metalloproteins}

The molecular metal ion docking in selected secreted metalloproteins was done manually on the basis of the template from MetalPDB by replacement of the coordinates into the proteins using PyMol (DeLano, 2002). The structures of the template and selected protein were aligned and coordinates of metal ion and ligand were saved. Coot 0.7.2 (Emsley and Cowtan, 2004) was used to merge both the pdb files. The docked proteins were visualized by PyMol for studying the interactions between metal ion(s) and amino acid residues.

\section{RESULTS}

The proteome scale investigation of $P$. syringae pv. lapsa for identification of $\mathrm{Fe}, \mathrm{Zn}$, and $\mathrm{Cu}$-binding proteins was carried out using the systematic bioinformatics approach (Figure 1). It was revealed that most of the proteins were $\mathrm{Zn}$-binding (307) followed by Fe (232) and Cu-binding (38) proteins. Zinc is known to be the most abundant metal ion in the living world and hence, the higher percentage of $\mathrm{Zn}$ was expected. Some proteins have interactions with more than two metal ions on the same or different active site. The grouping of $\mathrm{Fe} / \mathrm{Zn}$ was the most recurrent combination subsequently followed by $\mathrm{Zn} / \mathrm{Cu}$ and $\mathrm{Fe} / \mathrm{Cu}$ (Figure 2), respectively.

\section{Iron Binding Proteome of $\boldsymbol{P}$. syringae pv. lapsa}

It was identified that out of 4962 proteins of $P$. syringae pv. lapsa, a total of 286 have Fe-binding sequence motifs. Out of these, only 279 proteins were modeled by Phyre2 on the basis of homology. Using MIB and Ligplot ${ }^{+}$tools, it was identified that 232 proteins have sequence and structural motifs for either $\mathrm{Fe}^{2+}$ or $\mathrm{Fe}^{3+}$ ions. These identified Fe-binding proteins constitute about $4.7 \%$ of the total proteome. His, Glu, Asp, Asn, Arg, and Cys were the common interacting residues in the binding pocket of Fe-binding proteins. The order of interactions of protein and $\mathrm{Fe}$ ions are shown in Figure 3. The domain analysis of Fe-binding proteins showed the abundance of $\mathrm{ABC}$ transporter, TonB dependent receptors (TBDRs), aminotransferase, solute binding proteins (SBPs) and NADH flavin oxidoreductase/NADH oxidase (Nox) domains. On the basis of literature review of the identified domains Fe-binding proteins were further categorized in to 11 broad classes namely transport (116), metabolic process (75), response to oxidative stress (12), transcription regulation (9), DNA repair (8), cell signaling (3), RNA processing (3), protein folding (2), proteolysis (2), antimicrobial resistance (1), and protein biosynthesis (1). The detailed functional domain analysis is shown in Figure 4 and Supplementary Table S1. The subcellular localization of Fe-binding proteins was in accordance with their functional categories. The analysis revealed that most of the proteins involved in metabolic processes and response to oxidative stress were localized in the cytoplasm (106) while many of the transporter proteins were confined to inner-membrane (90), 


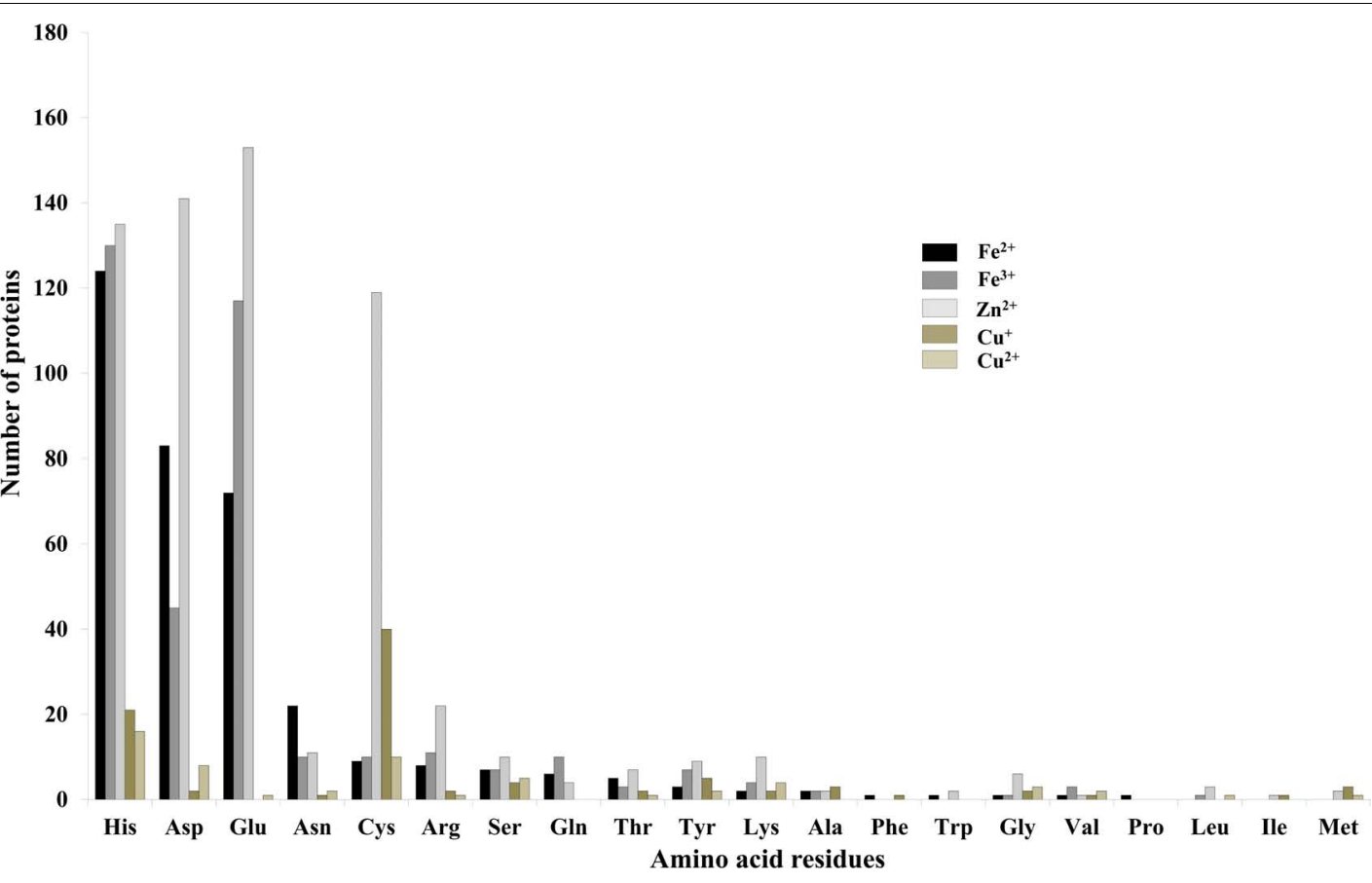

FIGURE 3 | Interactions of amino acid residues and metal ions. Bar diagram showing the interaction of amino acid residues with metal ions $\left(\mathrm{Fe}^{2+}, \mathrm{Fe}^{3+}, \mathrm{Zn}^{2+}, \mathrm{Cu}^{+}\right.$, and $\mathrm{Cu}^{2+}$ ). The Y-axis showing number of proteins and X-axis showing name of amino acid residues. Gln, Asp, His, Cys, Arg, and Asn were the most common interacting residues with different metal ions.

periplasmic space (20) and outer-membrane (14). Two proteins were found in extracellular space (Figure 5 and Supplementary Table S1). The enriched GO BP network of the identified Febinding proteins was configured on 11 kappa score groups with $83 \mathrm{BP}$ nodes and 278 edges. A total of 7 significant groups of GO terms (ATP hydrolysis coupled anion transmembrane transport, organic substance transport, nitrogen compound transport, ion transport, iron coordination entity transport, cellular-homeostasis and ROSs metabolic process) were identified (Figure 6). The analysis of the network was done to determine the importance of $\mathrm{Fe}$-binding protein-encoding genes in the regulation of BPs by the estimation of a number of interactions in which involvement of each single node was noted. The most connected GO terms were allied with transport (GO:0006810) having 66 links and transmembrane transport (GO:0055085) with 43 links (Supplementary Table S2). Therefore, we have found that GO BP network of Fe-binding proteins satisfies the results of domain-based functional classification. The homology search of $232 \mathrm{Fe}$-binding proteins with host proteome (Triticum aestivum) revealed that 103 proteins were non-homologous to bread wheat. Out of these 103 non-homologous proteins, 29 (19 Sec-dependent, 1 Tat-dependent and 9 non-classical) proteins were found to be putative secreted in nature without any transmembrane helix (Supplementary Table S3). These proteins were found to be localized in periplasm, outer-membrane and extracellular space and were functionally involved in transport, response to oxidative stress, proteolysis and metabolic processes (Table 1). The manual docking of the putative secreted Febinding proteins based on the template from MetalPDB database search showed that proteins have similar binding pockets as the template. This structural protein-Fe ion interaction analysis helps in understanding the structure based functional behavior of the proteins. The detailed summary has been given in Supplementary Figure S1 and Supplementary Table S4.

\section{Zinc Binding Proteome of $P$. syringae pv. lapsa}

A total of 466 proteins were predicted to have Zn-binding sequence motifs from the whole proteome of $P$. syringae pv. lapsa. Out of them, 450 proteins were modeled by Phyre 2 and 307 showed the presence of $\mathrm{Zn}$-binding sequence and structural patterns. The common interacting residues with $\mathrm{Zn}^{2+}$ ion was Glu, Asp, His and Cys (Figure 3). Short-chain dehydrogenase/reductase (SDR), response regulator receiver, alcohol dehydrogenase/GroES (ADH/GroES), ABC transporter and SBPs were major domains among Zn-binding proteins. Based on the literature survey we have functionally classified Zn-binding proteins into 12 different classes viz. metabolic process (135), transport (39), cell signaling (24), protein biosynthesis (23), DNA repair (17), proteolysis (17), response to oxidative stress (11), RNA processing (11), protein folding (8), transcription regulation (8), DNA replication (7) and antimicrobial resistance (7) (Figure 7 and Supplementary Table S5). The subcellular localization of Zn-binding proteins showed that 246 proteins were confined to the cytoplasm. Most of these cytoplasmic proteins belong to the category of metabolic process, protein biosynthesis, transcription regulation, DNA replication, DNA repair, protein folding and RNA processing. 


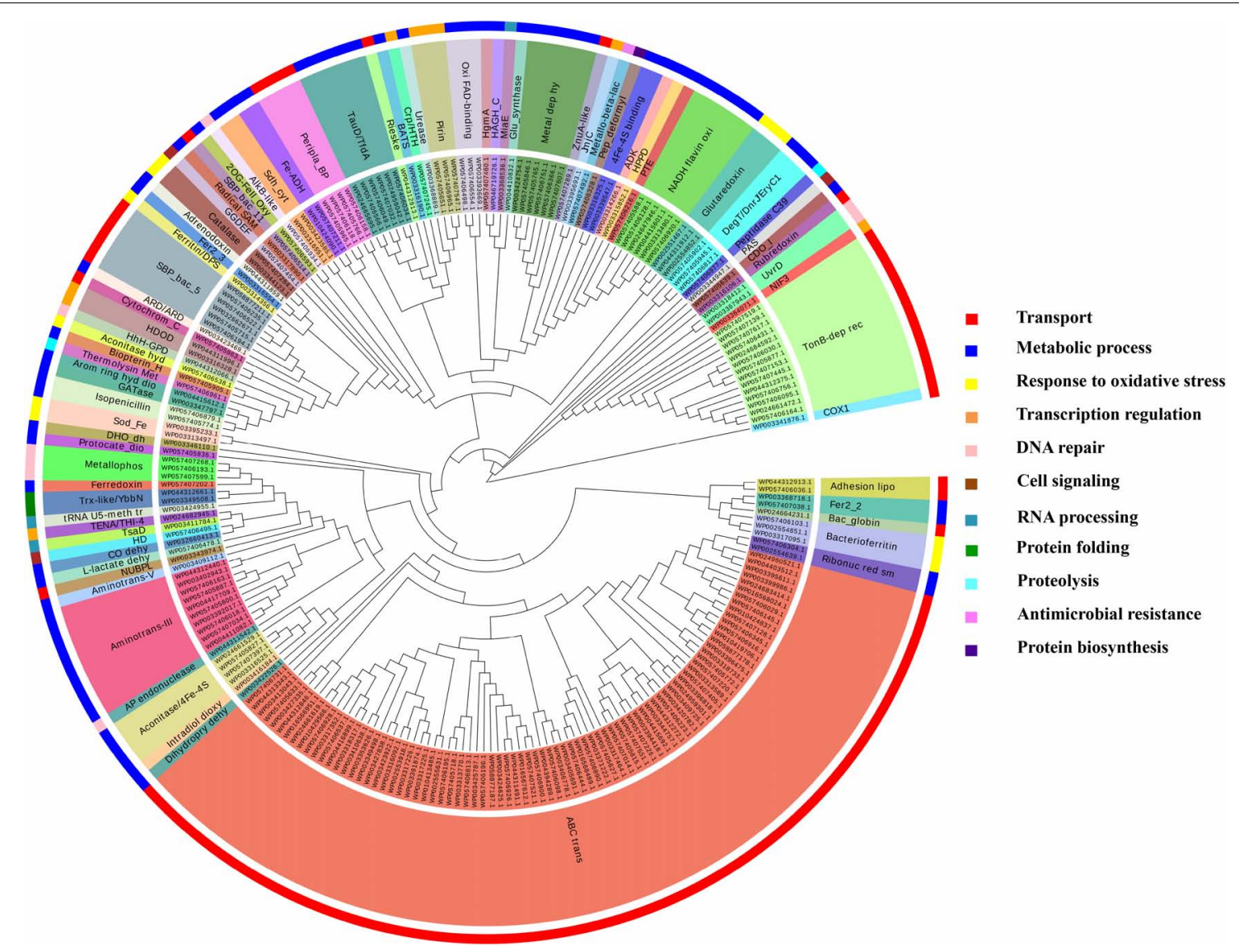

FIGURE 4 | Functional classification of Fe-binding proteins. The clustergram was generated by MEGA6 program (Tamura et al., 2013). The inner circle represents the sequence identifiers. The middle circle shows the functional domains/family of the respective sequence identifier. The color code given here is to represent only the outer circle which denote the broad classification of Fe-binding proteins on the basis of their biological roles. The most common domains were ABC transporters, TBDRs, SBPs, aminotransferase-III and NADH falvin-oxidoreductase. These proteins have diverse roles mainly in transport, metabolic processes and response to oxidative stress.

Twenty-nine proteins localized to the periplasm and 24 were confined to inner-membrane, many of them related to transport. Four outer-membrane and 4 extracellular proteins have also been identified which belong to the category of antimicrobial resistance and proteolysis. (Figure 5 and Supplementary Table S5). The GO BP functionally annotated network of Zn-binding proteins was constructed on 18 kappa score groups by ClueGO having 174 nodes and 679 edges. The network analysis showed 4 significant groups of GO terms (amino acid activation, tRNA aminoacylation, protein metabolic process and tRNA metabolic process) (Figure 8). The BP nodes macromolecule metabolic process (GO:0043170) and cellular nitrogen compound metabolic process (GO:0034641) were most connected GO terms with 91 and 90 links respectively (Supplementary Table S6). Additionally, some BP nodes showed alliance with more than two functional groups which signify possible involvement of their associated genes in the regulation of multiple BPs (Supplementary Table S6). A total of 148 non-homologous Zn-binding proteins were further selected after homology search with host proteome. Out of these 148 proteins, 31 (19 Sec-dependent, 1 Tat-dependent and 11 non-classical) were identified as putative Zn-binding secreted proteins having no transmembrane helix (Supplementary Table S7). Subcellularly these proteins confined to periplasm, outer-membrane and extracellular space (Table 1). The putative $\mathrm{Zn}$-binding secreted proteins were involved in transport, antimicrobial resistance, proteolysis, response to oxidative stress, metabolic process and DNA repair (Table 1 ). The $\mathrm{Zn}$ ion was manually docked in these identified secreted proteins on the basis of template obtained from MetalPDB which showed similar binding amino acid residues. The representative tertiary structure of each domain of putative secreted $\mathrm{Zn}$-binding proteins was shown in Supplementary Figure S2 and Supplementary Table S8.

\section{Copper Binding Proteome of $P$. syringae pv. lapsa}

We have found 45 proteins with $\mathrm{Cu}$-binding sequence motifs from the whole proteome of $P$. syringae pv. lapsa. Out of these, 44 proteins were modeled by Phyre2. Thirty-eight $\mathrm{Cu}$-binding proteins showed sequence and structural motifs either for $\mathrm{Cu}^{+}$or for $\mathrm{Cu}^{2+}$. Cys, His, Tyr, Ser and Met were common 


\section{0}

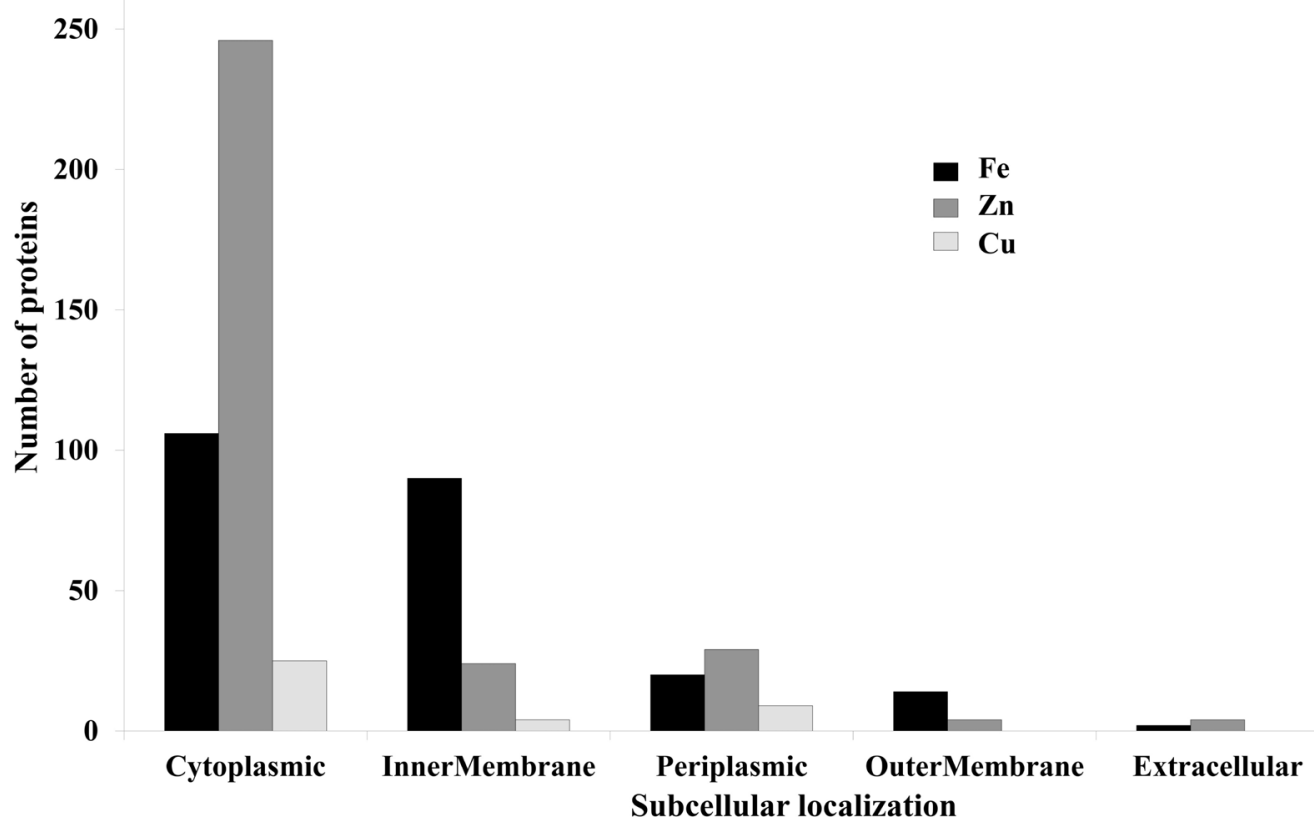

FIGURE 5 | Subcelluar-localization of predicted Fe, Zn, and Cu-binding proteins. This graph is showing subcellular localizations of the predicted metalloproteins. $X$-axis represents localization and $Y$-axis showing number of proteins. Most of the proteins were found to be localized in cytoplasm and inner-membrane.

interacting residues with $\mathrm{Cu}^{+}$ion and His, Cys and Asp were common interacting residues with $\mathrm{Cu}^{2+}$ ion (Figure 3). The functional domain analysis of identified $\mathrm{Cu}$-binding proteins indicates the major presence of ADH/GroES, Trx-like/YbbN, multiple Cu-oxidase and P-type ATPase domains. The literature studies of the domains present in these $\mathrm{Cu}$-binding proteins help us to categorize them into 6 broad classes which include metabolic process (18), response to oxidative stress (6), protein folding (6), transport (5), transcription regulation (2) and proteolysis (1) (Figure 9 and Supplementary Table S9). Twenty-five Cu-binding proteins found to be localized in the cytoplasm, which were generally involved in process of metabolism. Nine proteins were found in periplasm, most of them related to the category of response to oxidative stress. Four proteins localized to inner-membrane belong to transport category. (Figure 5 and Supplementary Table S9). The ClueGO functionally grouped annotation BP network of Cu-binding proteins showed 31 nodes and 87 edges at 4 kappa score groups (Figure 10). Four significant groups have BP nodes for cell redox homeostasis, positive regulation of metabolic process, generation of precursor metabolites and energy and response to toxic substances. The nodes representing positive regulation of metabolic process (GO:0009893) was the most connected GO terms with 21 links (Supplementary Table S10). Further, $16 \mathrm{Cu}$-binding proteins found to be non-homologous to host proteome and out of them 5 (4 Sec-dependent and 1 Tat-dependent) were found to be putative secreted in nature and none of them has transmembrane helix (Supplementary
Table S11). All the 5-putative secreted Cu-binding proteins were localized to the periplasm and functions in response to oxidative stress, transport, protein folding and proteolysis (Table 1). After manual docking on the basis of the template obtained from MetalPDB, we have found similar binding patterns for the putative secreted $\mathrm{Cu}$-binding proteins as that of the template (Supplementary Figure S3 and Supplementary Table S12).

\section{DISCUSSION}

The proportion of metalloproteins in the entire proteome varies from prokaryotes to eukaryotes (Dupont et al., 2010). The presented study based on the bioinformatics analysis of $\mathrm{Fe}, \mathrm{Zn}$, and $\mathrm{Cu}$-binding proteins of $P$. syringae pv. lapsa for their probable role in bacterial physiology and virulence. This study signifies the prediction of both sequence and structural metalloproteins motifs on the basis of datasets of MetalPDB (Andreini et al., 2013). A total of 577 metallproteins has been identified from $P$. syringae pv. lapsa which includes $232 \mathrm{Fe}, 307$ $\mathrm{Zn}$ and $38 \mathrm{Cu}$-binding proteins. The presence of metalloproteins obtained from $P$. syringae pv. lapsa proteome has conformity with earlier reports for $\mathrm{Fe}, \mathrm{Zn}$, and $\mathrm{Cu}$ proteomes of bacteria (Andreini et al., 2006, 2007, 2008). It was earlier reported that some proteins are specific to particular ligand while some proteins are highly promiscuous and may interact with one or more metal ions (Schreiber and Keating, 2011). This characteristic 


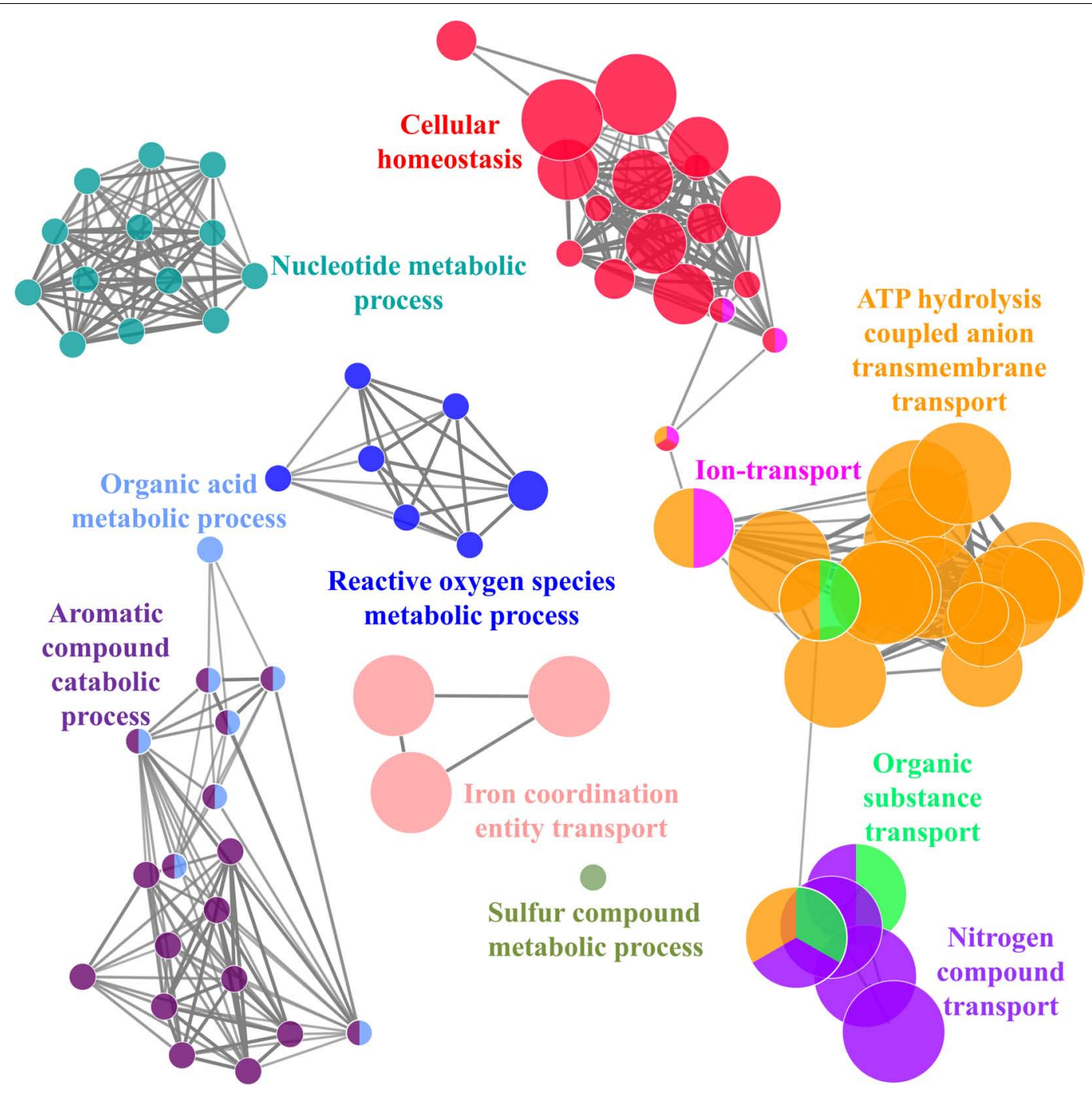

FIGURE 6 | The ClueGO functionally grouped annotation network of Fe-binding proteins constructed at kappa score $\geq 0.4$ showing 7 significant groups of GO terms (ATP hydrolysis coupled anion transmembrane transport, organic substance transport, nitrogen compound transport, ion transport, iron coordination entity transport, cellular homeostasis and ROSs metabolic process). Each circle represent particular BP node. Colors of node represent the group they belong. The node belongs to multiple groups shown by mixed coloring.

of protein is dependent on its structural properties such as conformational plasticity and amino acid residues at the catalytic site. Thirty-five Fe-binding proteins and $19 \mathrm{Cu}$-binding proteins share $\mathrm{Zn}$-binding motifs. Two $\mathrm{Cu}$-binding proteins share motifs with Fe-binding proteins and 3 proteins have motifs for 3 of the metal ions, i.e., $\mathrm{Fe}, \mathrm{Zn}$ and $\mathrm{Cu}$. All these are transition metals (Fe, $\mathrm{Zn}$, and $\mathrm{Cu}$ ) and therefore have a tendency to interact with amino acid residues of similar chemical nature. The most common interacting residues reported in the binding site of $\mathrm{Fe}, \mathrm{Zn}$, and $\mathrm{Cu}$-binding proteins were His, Asp, Glu, and Cys which were in accordance with previous reports that polar or charged amino acid involved in coordination of metal ion (Auld, 2001; Babor et al., 2008).

The functional domain analysis of Fe-binding proteins showed their major role in transport, metabolism and response to oxidative stress. The transporter Fe-binding proteins were enriched in the inner-membrane $\mathrm{ABC}$ transporter, outer-membrane TBDRs and periplasmic SBPs domains which may act as receptors for the transport of Fe ions and Fe bound complexes for maintenance of Fe-homeostasis (Taguchi et al., 2010; Tai et al., 2003; Tanaka et al., 2017). The Fe-binding proteins involved in different metabolic processes were mostly localized in the cytoplasm and were predominantly contain aminotransferase-III, Nox, metal dependent hydrolase and TauD/TfdA domains. The aminotransferase III have transaminase and pyridoxal phosphate binding activity which helps in catalyzing various biosynthetic processes (Marienhagen et al., 2005). The FMN binding and oxidoreductase activity of Nox domain also help to regulate various metabolic processes (Yamamoto et al., 2006). The metal-dependent hydrolases involved in the hydrolysis of the wide spectrum of substrates (Hernick and Fierke, 2013) and TauD/TfdA domain-containing 
TABLE 1 | Subcellular localization and functional domain analysis of secreted iron, zinc, and copper binding proteins.

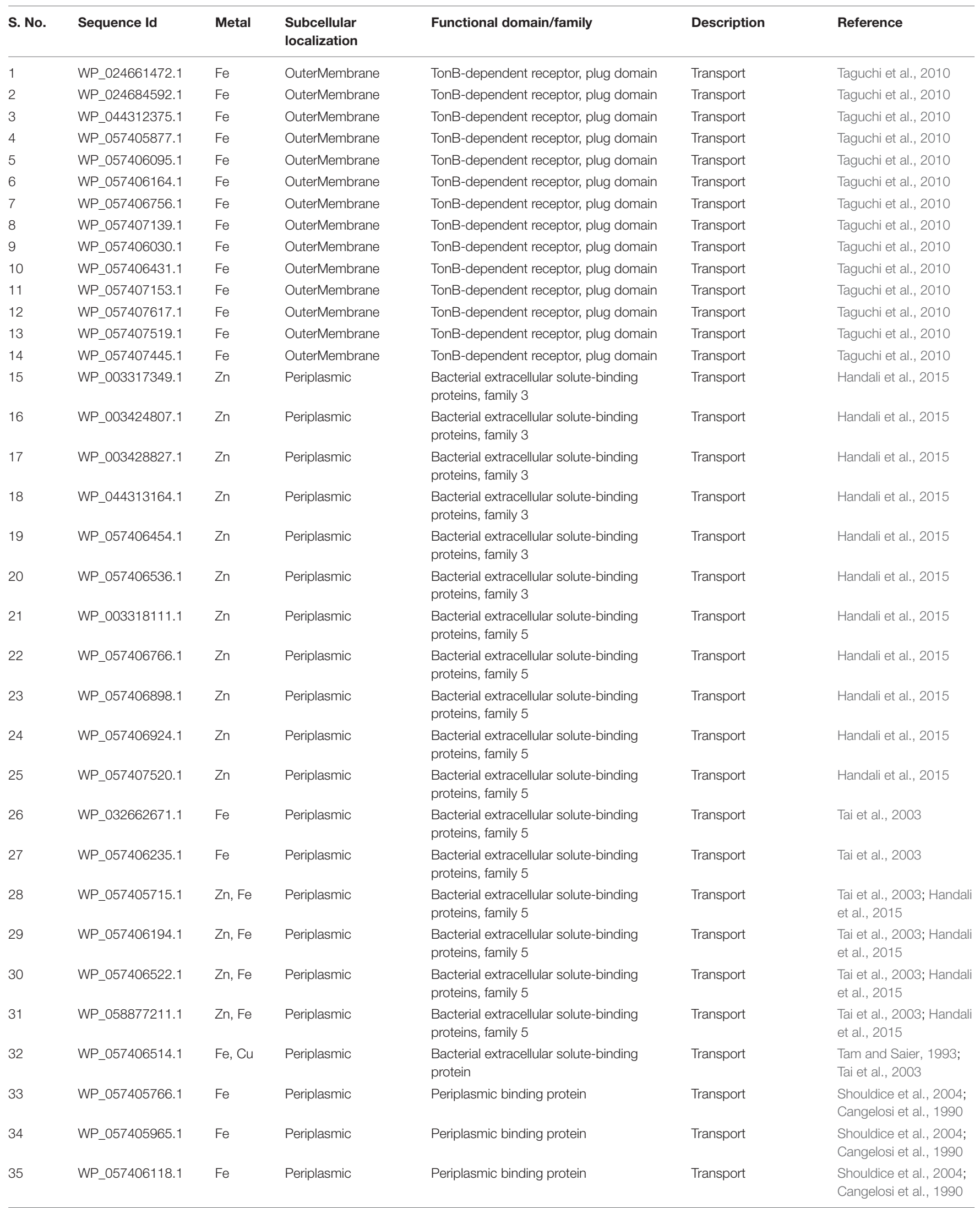


TABLE 1 | Continued

\begin{tabular}{|c|c|c|c|c|c|c|}
\hline S. No. & Sequence Id & Metal & $\begin{array}{l}\text { Subcellular } \\
\text { localization }\end{array}$ & Functional domain/family & Description & Reference \\
\hline 36 & WP_003346032.1 & $\mathrm{Zn}$ & Periplasmic & Periplasmic binding protein & Transport & Chandra et al., 2007 \\
\hline 37 & WP_003425596.1 & $\mathrm{Zn}$ & Periplasmic & Periplasmic binding protein & Transport & Chandra et al., 2007 \\
\hline 38 & WP_044312913.1 & $\mathrm{Fe}$ & Periplasmic & Adhesion lipoprotein & Transport & $\begin{array}{l}\text { Berne et al., 2015; } \\
\text { Ghazaei, } 2016\end{array}$ \\
\hline 39 & WP_057406036.1 & $\mathrm{Fe}$ & Periplasmic & Adhesion lipoprotein & Transport & $\begin{array}{l}\text { Berne et al., 2015; } \\
\text { Ghazaei, } 2016\end{array}$ \\
\hline 40 & WP_057406538.1 & $\mathrm{Fe}$ & Extracellular & Aconitase family & $\begin{array}{l}\text { Response to } \\
\text { oxidative stress }\end{array}$ & Kirchberg et al., 2012 \\
\hline 41 & WP_057407465.1 & $\mathrm{Zn}$ & Periplasmic & DJ-1/Pfpl family & $\begin{array}{l}\text { Response to } \\
\text { oxidative stress }\end{array}$ & Bankapalli et al., 2015 \\
\hline 42 & WP_057406401.1 & $\mathrm{Zn}, \mathrm{Cu}$ & Periplasmic & $\begin{array}{l}\text { Copper/zinc superoxide dismutase } \\
\text { (SODC) }\end{array}$ & $\begin{array}{l}\text { Response to } \\
\text { oxidative stress }\end{array}$ & $\begin{array}{l}\text { Fones and Preston, } \\
2012\end{array}$ \\
\hline 43 & WP_057407566.1 & $\mathrm{Zn}, \mathrm{Cu}$ & Periplasmic & Azurin family & $\begin{array}{l}\text { Response to } \\
\text { oxidative stress }\end{array}$ & Swingle et al., 2008 \\
\hline 44 & WP_057406961.1 & $\mathrm{Fe}, \mathrm{Zn}$ & Extracellular & $\begin{array}{l}\text { Thermolysin metallopeptidase, } \\
\text { alpha-helical domain/Peptidase M4 }\end{array}$ & Proteolysis & Kyostio et al., 1991 \\
\hline 45 & WP_003411605.1 & $\mathrm{Zn}$ & Extracellular & Peptidase M10 serralysin & Proteolysis & Zhang et al., 1999 \\
\hline 46 & WP_057406970.1 & $\mathrm{Zn}$ & Extracellular & Peptidase M10 serralysin & Proteolysis & Zhang et al., 1999 \\
\hline 47 & WP_044312611.1 & $\mathrm{Zn}, \mathrm{Cu}$ & Periplasmic & Trypsin & Proteolysis & $\begin{array}{l}\text { Tripathi and } \\
\text { Sowdhamini, } 2008\end{array}$ \\
\hline 48 & WP_057407431.1 & $\mathrm{Zn}$ & Periplasmic & Beta-lactamase & $\begin{array}{l}\text { Antimicrobial } \\
\text { resistance }\end{array}$ & Bebrone, 2007 \\
\hline 49 & WP_003316096.1 & $\mathrm{Zn}$ & OuterMembrane & Peptidase family M23 & $\begin{array}{l}\text { Antimicrobial } \\
\text { resistance }\end{array}$ & Grabowska et al., 2015 \\
\hline 50 & WP_003422785.1 & $\mathrm{Zn}$ & OuterMembrane & Peptidase family M23 & $\begin{array}{l}\text { Antimicrobial } \\
\text { resistance }\end{array}$ & Grabowska et al., 2015 \\
\hline 51 & WP_057405551.1 & $\mathrm{Zn}$ & OuterMembrane & Peptidase family M23 & $\begin{array}{l}\text { Antimicrobial } \\
\text { resistance }\end{array}$ & Grabowska et al., 2015 \\
\hline 52 & WP_057406372.1 & $\mathrm{Zn}$ & OuterMembrane & Peptidase family M23 & $\begin{array}{l}\text { Antimicrobial } \\
\text { resistance }\end{array}$ & Grabowska et al., 2015 \\
\hline 53 & WP_003416184.1 & $\mathrm{Fe}$ & Periplasmic & Intradiol ring-cleavage dioxygenase & Metabolic process & Bianchetti et al., 2013 \\
\hline 54 & WP_016567277.1 & $\mathrm{Zn}$ & Periplasmic & Isochorismatase, RutB & Metabolic process & Liu et al., 2014 \\
\hline 55 & WP_003317093.1 & $\mathrm{Zn}$ & Periplasmic & Single-strand binding protein family & DNA repair & Citovsky et al., 1988 \\
\hline 56 & WP_003424002.1 & $\mathrm{Cu}$ & Periplasmic & Copper chaperone SCO1/SenC & Protein folding & $\begin{array}{l}\text { Seib et al., 2003; } \\
\text { Lohmeyer et al., } 2012\end{array}$ \\
\hline
\end{tabular}

proteins have oxidation-reduction activity to catalyze the discharge of sulfite from taurine during sulfur starvation (Elkins et al., 2002). The Fe-binding proteins belonging to the category of response to oxidative stress mostly contain bacterioferritin, catalase and iron/manganese superoxide dismutase (Fe/Mn SOD) domains. Bacterioferritin (iron storage proteins) have ferroxidase activity which assists detoxification and protection from free radicals (Andrews, 1998). The catalase and Fe/Mn SOD catalyzes the conversion of free radicals and super-radicals to molecular oxygen which helps in regulating cellular redox homeostasis (Fones and Preston, 2012). The GO BP network analysis of Fe-binding proteins supports their functional domain classification, as the network also indicate their major role in transport, metabolism, cellular response to homeostasis and ROS detoxification. This analysis is supported by the earlier study that Fe-binding proteins have profound effect on growth, metabolism and survival of $P$. syringae (Kim et al., 2009).

The functional classification of $\mathrm{Zn}$-binding proteins showed that metabolic process, transport, cell signaling and protein biosynthesis were most enriched functional categories. The cytoplasmic proteins with domains SDR and ADH/GroES were commonly found in metabolic process. SDR have oxidoreductase activity to catalyze amino acid, carbohydrate, lipid and xenobiotic metabolism (Kavanagh et al., 2008). $\mathrm{ADH} / \mathrm{GroES}$ also catalyzes oxidation-reduction reactions during alcohol fermentation and its Gro-ES like fold helps in maintaining its structural integrity (Zheng et al., 2017). The transport category of $\mathrm{Zn}$-binding proteins also showed the main presence of integral membrane ABC transporter and periplasmic SBPs domain like Fe-binding proteins. As discussed above both of these domains help in transport of metal ions and other substrates (Tanaka et al., 2017). The proteins in the cell signaling category mainly contain response regulator receiver domain which influences a cellular response through phosphorylationactivated switches (Gao et al., 2007). Elongation factor $\mathrm{Tu}$ GTP binding domain which causes GTP dependent elongation of polypeptide chain during translation and tRNA synthase which catalyzes the amino acid addition to its cognate tRNA 


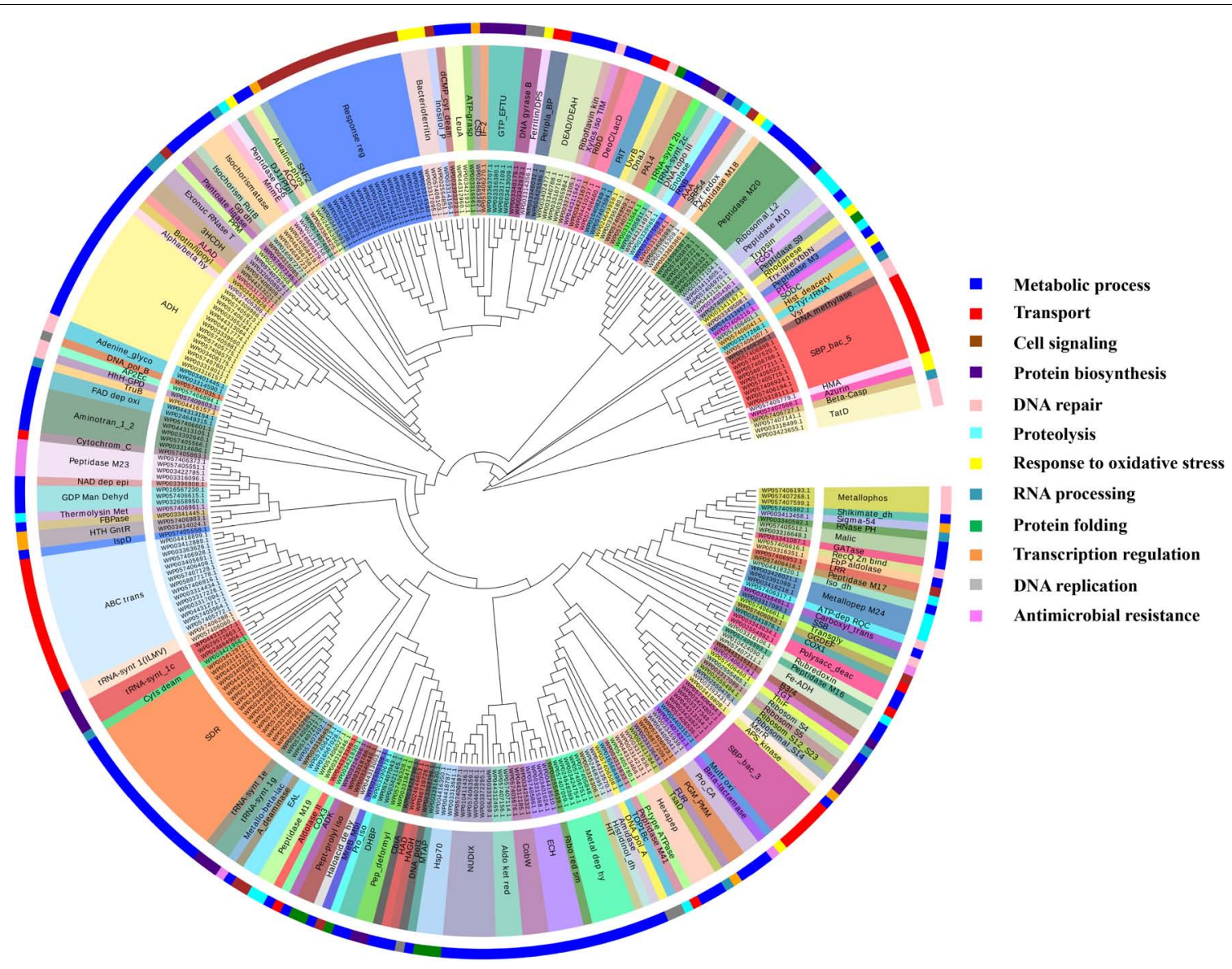

FIGURE 7 | Functional classification of identified Zn-binding proteins. The clustergram of Zn-binding proteins clustered by Mega (Tamura et al., 2013). The inner circle denotes the sequence identifiers. The middle circle represents the functional domains/family of the respective sequence identifier. The outer circle shows the broad classification of $\mathrm{Zn}$-binding proteins on the basis of their biological roles. The color code given here represents the outer circle only. The Zn-binding proteins predominantly showed the presence of SDR, ADH/GroES, ABC transpoters, response regulators and SBPs domains. Most of the Zn-binding proteins were play significant roles in metabolic processes, transport, cell signaling, protein biosynthesis and protein folding.

were majorly present in the category of protein biosynthesis (Andersen et al., 2003; Banerjee et al., 2004). The GO enriched BP network analysis of $\mathrm{Zn}$-binding proteins showed the conformity with functional domain-based classification which revealed that most of the proteins involved in metabolic processes (protein, purine, organic acid, DNA and RNA), transport (ions, amino acid and transition metals), tRNA aminoacylation, amino acid activation and translation elongation. The analysis was also in accordance with the previous findings that $\mathrm{Zn}$-binding proteins play a wide role in various biological processes and contribute in bacterial growth and proliferation (Murakami and Hirano, 2008; Maret, 2013).

The functional classification of $\mathrm{Cu}$-binding proteins was enriched in the categories of metabolic process, response to oxidative stress and transport. Several metalloproteins were reported to be highly promiscuous in nature and could bind with one or more metal ions (Pordea, 2015). The proteins found in metabolic process mainly contain ADH/GroES and Glutathione S-transferase (GST) and Carbonic anhydrase (CA) domains. Both $\mathrm{ADH} / \mathrm{GroES}$ and $\mathrm{CA}$ protein were reported as Zn-binding metalloenzymes (Christianson and Fierke, 1996; Bergman et al., 2008). The role of $\mathrm{ADH} / \mathrm{GroES}$ in alcohol fermentation has already discussed above. CA involved in reversible hydration of carbon dioxide and causes interference in $\mathrm{pH}$ regulation other physiological processes of bacteria (Lionetto et al., 2016). However, no in vivo study validates the binding of $\mathrm{Cu}$ ion to $\mathrm{ADH}$ and $\mathrm{CA}$. Earlier in vitro studies showed that $\mathrm{Cu}$ ion can substitute $\mathrm{Zn}$ ion in $\mathrm{ADH}$ (Vanni et al., 2002) and CA (Nettles et al., 2015). Since, Cu is able to substitute $\mathrm{Zn}$ from its binding site, therefore, it can be inferred that the proteins may have affinity for $\mathrm{Cu}$ ions as well (Nettles et al., 2015). GST catalyzes the nucleophilic addition of tripeptide glutathione to the substrate having reactive electrophilic functional groups which aid in biodegradative metabolism of xenobiotic compounds and their detoxification (Armstrong, 1991). Although, there are no direct evidences that $\mathrm{Cu}$ ion bind to GST, but biochemical studies showed that GST proteins have binding affinity for $\mathrm{Cu}$ ion (Tang et al., 1996; Chen et al., 2015). The activity of GST is inhibited by Cu-binding which leads to inactivation of enzyme. This enzyme inactivation is 


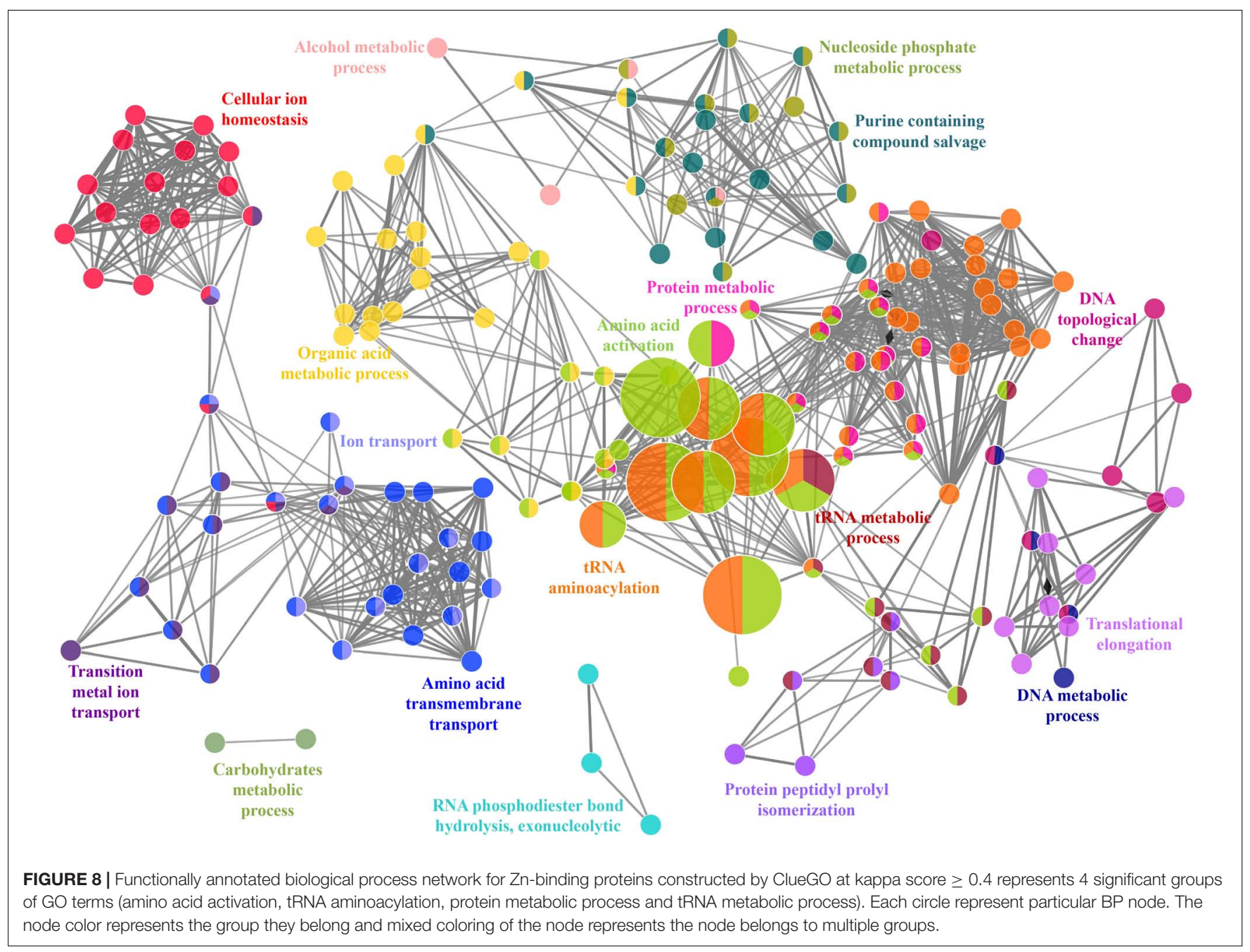

dose $(\mathrm{Cu}$ concentration) and time-dependent (Tang et al., 1996; Shi et al., 2014). It is still not clear whether direct binding of $\mathrm{Cu}$ to GST have a significant role in $\mathrm{Cu}$-homeostasis or not which can be future thirst area. In the category of response to oxidative stress, most of the $\mathrm{Cu}$-binding proteins belong to periplasmic multicopper oxidase (MCO), Copper/zinc superoxide dismutase ( $\mathrm{Cu} / \mathrm{Zn}$ SODs) domain azurin and alkyl hydroperoxide reductase/thiol-specific antioxidant (AhpC/TSA) family. MCO catalyzes oxidation-reduction reactions to maintain oxidative stress response (Sitthisak et al., 2005). Cu/Zn SODs have dismutase activity which catalyzes the conversion of super-radicals to $\mathrm{H}_{2} \mathrm{O}_{2}$ and molecular oxygen (Fones and Preston, 2012). Azurin also acts as redox sensor and protect the cell from radical burst (Swingle et al., 2008). Earlier a protein of AhpC/TSA family has been reported in Pseudomonas putida which have specificity for $\mathrm{Cu}$ ion and have antioxidant activity to encounter oxidative stress (Miller et al., 2009). The inner-membrane P-type ATPases, and cytochrome c oxidase (COX) domains were mainly found in transport category of the Cu-binding proteins. The inner-membrane P-type ATPases of bacteria involved in the ATP dependent export of $\mathrm{Cu}$ ion during $\mathrm{Cu}$ toxicity in their cytoplasm which aid in maintaining $\mathrm{Cu}$ - homeostasis (Arguello et al., 2011). The COX enzyme is the last enzyme in electron transport chain, it receives the electron from cytochrome $\mathrm{c}$ molecules and transport them to oxygen coupled to proton translocation, which results in the reduction of oxygen to water (Ludwig, 1987). The GO enriched $\mathrm{BP}$ analysis of $\mathrm{Cu}$-binding proteins confirms their involvement in the regulation of metabolic processes, redox homeostasis and response to reactive species which is also in accordance with their functional domain analysis.

The importance of metalloproteins in overall life processes makes their availability essential to all the organisms. But the excess of these metal ions is toxic to cell and therefore, metal ions concentration must be controlled tightly (Chandrangsu et al., 2017). Previously, it was documented that secreted proteins are major virulence factor of the bacteria which disrupt the normal functions of the host after interactions with the receptors of the defense system of the host (Ichinose et al., 2013). The metal ions uptake, storage and utilization also contribute to the bacterial virulence. Earlier, it was reported that the metal ions co-regulate the expression of secreted proteins and endorse their functions 


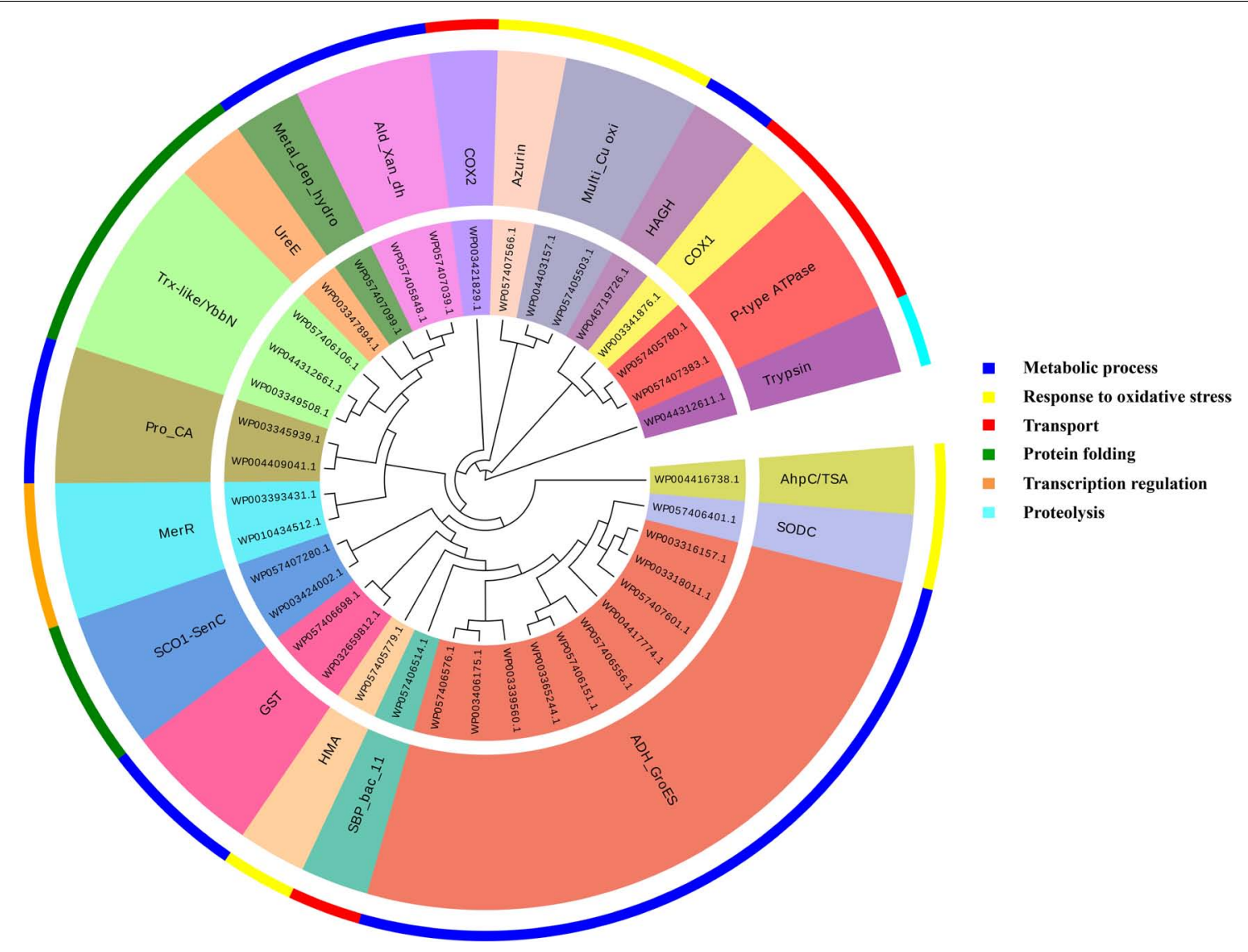

FIGURE 9 | Functional classification of identified Cu-binding proteins. Cu-binding proteins enlisted in the form of clustergram where the inner circle denotes the sequence identifiers. The middle circle represents the functional domains/family of the respective sequence identifier. The outer circle denotes the broad classification of Cu-binding proteins on the basis of their biological roles and color code here represents the outer circle only. Most of the Cu-binding proteins found to carry out the function of metabolism having ADH/GroES domain and protein which function in transport have P-type ATPase, COX and SBP domains.

of virulence (Sharma et al., 2017). In the present study, we have identified putative $\mathrm{Fe}, \mathrm{Zn}$, and $\mathrm{Cu}$-binding secreted proteins which were exclusively present in P. syringae pv. lapsa but not in host (Triticum aestivum). So, these candidate metalloproteins may act as suitable targets to design metal-based antimicrobial agents.

The whole proteome of $P$. syringae pv. lapsa comprised of 29, 31 and 5 putative secreted $\mathrm{Fe}, \mathrm{Zn}$, and $\mathrm{Cu}$-binding proteins respectively that varies in function from transport, response to oxidative stress, proteolysis, antimicrobial resistance, metabolic process, protein folding and DNA repair. We have found 39 transporter proteins, out of these 14 proteins were predicted as outer-membrane TBDRs proteins. As discussed above TBDRs may involve in the transport of $\mathrm{Fe}$-siderophore complexes and help in maintaining Fe-homeostasis in bacteria. Earlier, a link has already been confirmed between Fe-siderophore uptake, biofilm formation, quorum sensing and virulence during plant-pathogen interactions (Taguchi et al., 2010). Among 39 transporter proteins, 18 were SBPs. Out of these 18 SBPs, 11 proteins have an affinity for $\mathrm{Zn}, 2$ have affinity for Fe while 4 proteins have capability to bind with both $\mathrm{Fe}$ and $\mathrm{Zn}$ and 1 protein have affinity for $\mathrm{Fe}$ and $\mathrm{Cu}$ ion. It was also reported that
SBPs act as receptors for import of metal ions that contribute in metal-homeostasis and virulence of pathogenic bacteria (Tam and Saier, 1993; Tai et al., 2003; Handali et al., 2015). In agro-bacterial species, the periplasmic binding proteins (PBPs) are needed for metal-homeostasis, virulence and extracellular signaling between bacterial parasite and the host plant (Cangelosi et al., 1990; Shouldice et al., 2004; Chandra et al., 2007). We have identified 5 PBPs which may play important role in the transport of ions. Out of 5 PBPs, 3 have the capability to bind $\mathrm{Fe}$ and 2 proteins have an affinity for $\mathrm{Zn}$ ion. Two periplasmic adhesion lipoproteins have also been found in the class of transport. Earlier studies provide evidences that adhesion lipoproteins help in transport of $\mathrm{Fe}$ ions, attachment and adherence of the bacteria into the host and contribute in virulence (Berne et al., 2015; Ghazaei, 2016). The structural analysis of putatively secreted transporter metalloproteins showed that the most common interacting residues were Tyr, Phe, Trp, Asp, Lys and Ala in the binding site of TBDRs, SBPs and PBPs, which were similar to their template structures. These results support the previous finding that aromatic residues contribute in membrane protein interactions (Cobessi et al., 2005). 


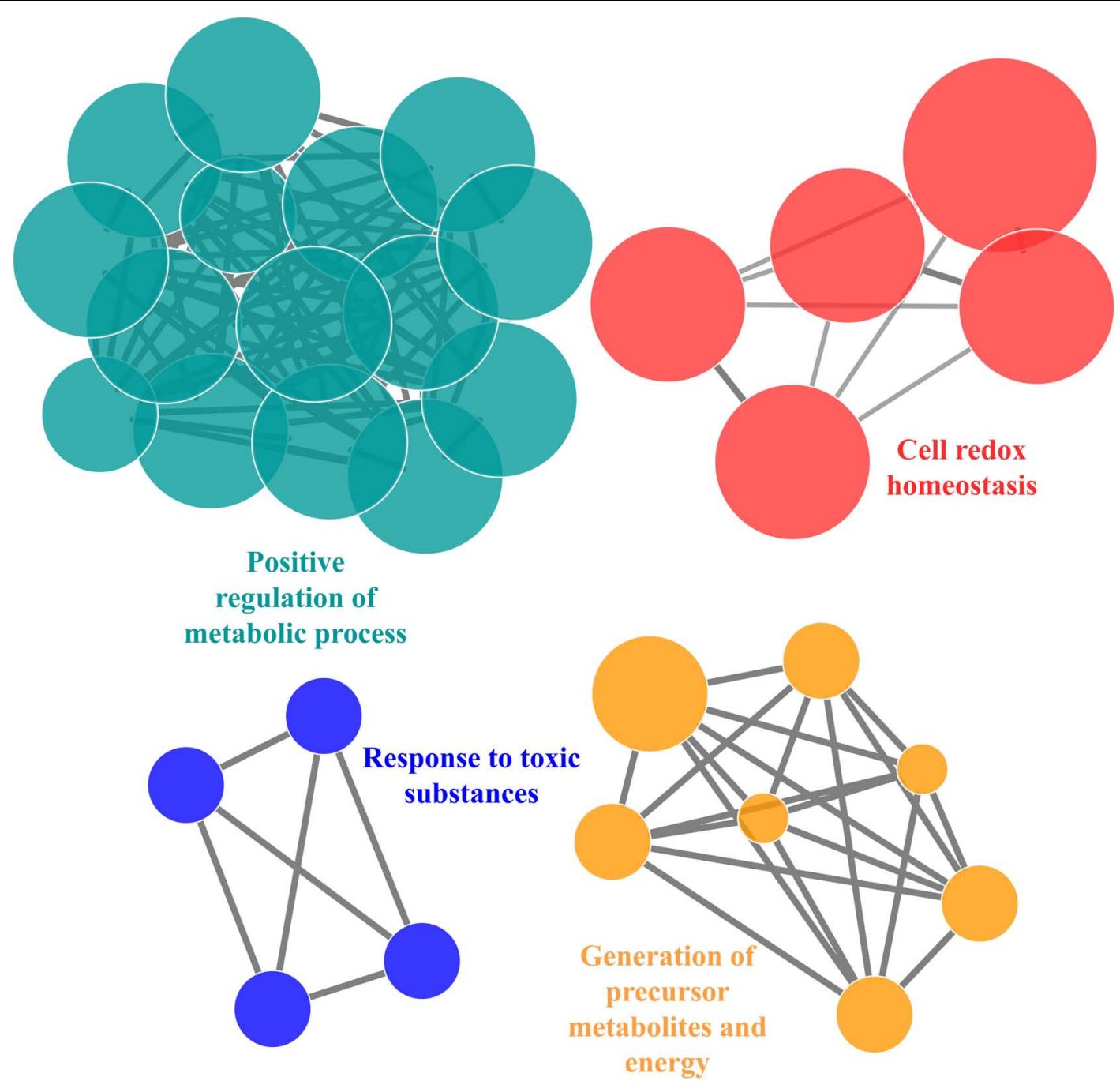

FIGURE 10 | The functionally biological process annotated network for Cu-binding proteins constructed by ClueGO at kappa score $\geq 0.4$ represents 4 significant groups of GO terms (positive regulation of metabolic process, cell redox homeostasis, generation of metabolites and energy, response to oxidative stress). Each circle represent particular BP node and the node color represent the group they belong.

We have found 4 putative secreted metalloproteins in the category of response to oxidative stress. One of which is a Fe-binding aconitase hydratase extracellular protein. The aconitase enzyme contains iron-sulfur cluster involved in TCA cycle and their role in the protection from ROSs has also been reported earlier in Xanthomonas campestris pv. vesicatoria (Kirchberg et al., 2012). A Zn-binding protein belongs to DJ/Pfpl family were also found to respond to oxidative stress. Earlier reports indicate that the DJ/Pfpl family containing proteins have a crucial role in redox homeostasis regulation (Bankapalli et al., 2015). The other two proteins involved in response to oxidative stress have binding affinity for both $\mathrm{Cu}$ and $\mathrm{Zn}$ ions. One of which has $\mathrm{Cu} / \mathrm{Zn}$ SODs and another one has azurin domain. As discussed above the $\mathrm{Cu} / \mathrm{Zn}$ SODs are well known for their high tolerance to oxidative stress and defense activities (Fones and Preston, 2012). It was also previously published that periplasmic azurin protein co-regulate the function of the gene needed for siderophore synthesis, response to oxidative stress and therefore, it may contribute to the virulence (Swingle et al., 2008).

In the category of proteolysis, we have found 3 extracellular and 1 periplasmic putatively secreted metalloproteins. Out of 3 extracellular proteins, one was thermolysin metallopeptidase (Peptidase M4) and other two were peptidase M10 serrlysin proteins. The thermolysin metallopeptidase protein has binding site for both Fe and Zn metal ions (Holland et al., 1995). Earlier findings showed that thermolysin proteases play important role in the degradation of peptic cellwall component of host plant and aid in virulence of the phytopathogen (Kyostio et al., 1991). The peptidase M10 serrlysin is already known for its Zn-binding affinity and ability to degrade and colonize the host cell (Zhang et al., 1999). A periplasmic putative secreted protein belongs to trypsin family was also found in the class of proteolysis which has an affinity for both $\mathrm{Zn}$ as well as $\mathrm{Cu}$. It was previously reported 
that trypsin requires metal ion for its structural stability, induces host cell lysis and further help to raise the virulence of bacteria (Kyostio et al., 1991; Tripathi and Sowdhamini, 2008; Li et al., 2018).

We have identified 5 putative secreted $\mathrm{Zn}$-binding proteins in the class of antimicrobial resistance. One of them was periplasmic $\beta$-lactamase protein, and other 4 were outer-membranic peptidase M23 proteins. Earlier studies suggested that $\beta$-lactamase and peptidase M23 domain containing proteins play important role in antimicrobial resistance by interfering with the synthesis of peptidoglycan of the cell wall (Bebrone, 2007; Grabowska et al., 2015).

We have found two periplasmic proteins involved in metabolic processes. Among them, one was a periplasmic Fe-binding intradiol ring-cleavage dioxygenase which may be involved in metabolic degradation of aromatic compounds. It was previously documented that intradiol deoxygenase destroys the precursors required for lignin biosynthesis by the plant (Bianchetti et al., 2013) and aid in the invasion of the phytopathogen. The other protein was periplasmic $\mathrm{Zn}$-binding isochorismatase which may be involved in the regulation of metabolic pathways. It is well-known fact that the isochroismatase proteins disrupt the plant salicylate metabolism by restraining the activity of its precursor and play indispensable role in the plant-pathogen interactions (Liu et al., 2014). We have identified 1 periplasmic single-strand $\mathrm{Zn}$-binding proteins which may be involved in DNA repair and transformation. Our findings are supported by the earlier study that single-strand binding proteins are essential for T-strand production, DNA repair and virulence (Citovsky et al., 1988). We have found a periplasmic copper chaperone SCO1/SenC in the class of protein folding. Copper chaperone SCO1/SenC is primarily required for the proper assembly of COX (Lohmeyer et al., 2012). Additionally, the thiol:disulfide oxidoreductase or peroxiredoxin activity of SCO1/SenC helps in protection of bacteria against oxidative stress (Seib et al., 2003). This comprehensive in silico report on $\mathrm{Fe}, \mathrm{Zn}$ and $\mathrm{Cu}$-binding proteins of $P$. syringae $\mathrm{pv}$. lapsa provide us evidence that metalloproteins, belonging to various protein families perform diverse range of biological functions and play crucial role in its normal growth, survival and pathogenesis. The obtained results related to secreted metalloproteins could be further investigated in more details by experimental approaches. This will further help to understand their mechanistic insight

\section{REFERENCES}

Altschul, S. F., Gish, W., Miller, W., Myers, E. W., and Lipman, D. J. (1990). Basic local alignment search tool. J. Mol. Biol. 215, 403-410. doi: 10.1016/S00222836(05)80360-2

Andersen, G. R., Nissen, P., and Nyborg, J. (2003). Elongation factors in protein biosynthesis. Trends Biochem. Sci. 28, 434-441. doi: 10.1016/S0968-0004(03) 00162-2

Andreini, C., Banci, L., Bertini, I., Elmi, S., and Rosato, A. (2007). Non-heme iron through the three domains of life. Proteins 67, 317-324. doi: 10.1002/prot. 21324

Andreini, C., Banci, L., Bertini, I., and Rosato, A. (2006). Zinc through the three domains of life. J. Proteome Res. 5, 3173-3178. doi: 10.1021/pr060 3699 in plant-pathogen interactions, to control phytopathogenic infections in the crop plants and to develop sustainable agriculture.

\section{CONCLUSION}

In the present study a systemic bioinformatics approach has been used to predict the $\mathrm{Fe}, \mathrm{Zn}$, and $\mathrm{Cu}$-binding proteome of $P$. syringae pv. lapsa, at the sequence and structural levels. It was observed that the identified metalloproteins perform a diverse range of biochemical and metabolic functions. This signifies the fact that metalloproteins are vital for growth and proliferation of $P$. syringae pv. lapsa. The study also provides the repository of putative secreted $\mathrm{Fe}, \mathrm{Zn}$, and $\mathrm{Cu}$-binding proteins which may serve as the primer to perform the experimental validation. This will help to understand the role of putative secreted metal binding proteins in plant-pathogen interactions and to develop new strategies to control plant disease which may further accelerate the healthy agricultural yield.

\section{AUTHOR CONTRIBUTIONS}

SV and AS conceived the idea. AS has done identification of metalloproteins, curation and analysis of the data. AS and DS performed the structural analysis. AS wrote the manuscript. SV edited the manuscript.

\section{ACKNOWLEDGMENTS}

SV lab was funded by the Department of Biotechnology, Government of India. The authors duly acknowledge the Central University of Himachal Pradesh for providing computational facilities. AS and DS acknowledge UGC for providing Ph.D. fellowships.

\section{SUPPLEMENTARY MATERIAL}

The Supplementary Material for this article can be found online at: https://www.frontiersin.org/articles/10.3389/fmicb. 2018.01838/full\#supplementary-material

Andreini, C., Banci, L., Bertini, I., and Rosato, A. (2008). Occurrence of copper proteins through the three domains of life: a bioinformatic approach. J. Proteome Res. 7, 209-216. doi: 10.1021/pr070480u

Andreini, C., Cavallaro, G., Lorenzini, S., and Rosato, A. (2013). MetalPDB: a database of metal sites in biological macromolecular structures. Nucleic Acids Res. 41, D312-D319. doi: 10.1093/nar/gks1063

Andrews, S. C. (1998). Iron storage in bacteria. Adv. Microb. Physiol. 40, 281-351. doi: $10.1038 / 279015 \mathrm{a} 0$

Arguello, J. M., Gonzalez-Guerrero, M., and Raimunda, D. (2011). Bacterial transition metal $\mathrm{P}(1 \mathrm{~B})$-ATPases: transport mechanism and roles in virulence. Biochemistry 50, 9940-9949. doi: 10.1021/bi201418k

Armstrong, R. N. (1991). Glutathione S-transferases: reaction mechanism, structure, and function. Chem. Res. Toxicol. 4, 131-140. doi: 10.1021/ tx00020a001 
Ashburner, M., Ball, C. A., Blake, J. A., Botstein, D., Butler, H., Cherry, J. M., et al. (2000). Gene ontology: tool for the unification of biology. Nat. Genet. 25, 25-29. doi: $10.1038 / 75556$

Auld, D. S. (2001). Zinc coordination sphere in biochemical zinc sites. Biometals 14, 271-313. doi: 10.1023/A:1012976615056

Babor, M., Gerzon, S., Raveh, B., Sobolev, V., and Edelman, M. (2008). Prediction of transition metal-binding sites from apo protein structures. Proteins 70, 208-217. doi: 10.1002/prot.21587

Banerjee, R., Dubois, D. Y., Gauthier, J., Lin, S. X., Roy, S., and Lapointe, J. (2004). The zinc-binding site of a class I aminoacyl-tRNA synthetase is a SWIM domain that modulates amino acid binding via the tRNA acceptor arm. Eur. J. Biochem. 271, 724-733. doi: 10.1111/j.1432-1033.2003.03976.x

Bankapalli, K., Saladi, S. D., Awadia, S. S., Goswami, A. V., Samaddar, M., and D'Silva, P. (2015). Robust glyoxalase activity of Hsp31, a ThiJ/DJ-1/PfpI family member protein, is critical for oxidative stress resistance in Saccharomyces cerevisiae. J. Biol. Chem. 290, 26491-26507. doi: 10.1074/jbc.M115. 673624

Bebrone, C. (2007). Metallo- $\beta$-lactamases (classification, activity, genetic organization, structure, zinc coordination) and their superfamily. Biochem. Pharmacol. 74, 1686-1701. doi: 10.1016/j.bcp.2007.05.021

Bendtsen, J. D., Jensen, L. J., Blom, N., Von Heijne, G., and Brunak, S. (2004a). Feature-based prediction of non-classical and leaderless protein secretion. Protein Eng. Des. Sel. 17, 349-356. doi: 10.1093/protein/gzh037

Bendtsen, J. D., Nielsen, H., Von Heijne, G., and Brunak, S. (2004b). Improved prediction of signal peptides: signalP 3.0. J. Mol. Biol. 340, 783-795. doi: 10 . 1016/j.jmb.2004.05.028

Bendtsen, J. D., Nielsen, H., Widdick, D., Palmer, T., and Brunak, S. (2005). Prediction of twin-arginine signal peptides. BMC Bioinformatics 6:167. doi: 10.1186/1471-2105-6-167

Bergman, T., Zhang, K., Palmberg, C., Jörnvall, H., and Auld, D. S. (2008). Zinc binding to peptide analogs of the structural zinc site in alcohol dehydrogenase: implications for an entatic state. Cell. Mol. Life Sci. 65, 4019-1027. doi: 10.1007/ s00018-008-8379-5

Berne, C., Ducret, A., Brun, Y. V., and Hardy, G. G. (2015). Adhesins involved in attachment to abiotic surfaces by gram-negative bacteria. Microbiol. Spectr. 3:10.1128/microbiolspec.MB-0018-2015. doi: 10.1128/microbiolspec. MB-0018-2015

Bianchetti, C. M., Harmann, C. H., Takasuka, T. E., Hura, G. L., Dyer, K., and Fox, B. G. (2013). Fusion of dioxygenase and lignin-binding domains in a novel secreted enzyme from cellulolytic streptomyces sp. SIRexaa-e. J. Biol. Chem. 288, 18574-18587. doi: 10.1074/jbc.M113.475848

Bindea, G., Mlecnik, B., Hackl, H., Charoentong, P., Tosolini, M., Kirilovsky, A., et al. (2009). ClueGO: a cytoscape plug-in to decipher functionally grouped gene ontology and pathway annotation networks. Bioinformatics 25, 1091-1093. doi: 10.1093/bioinformatics/btp101

Bowman, S. E. J., Bridwell-Rabb, J., and Drennan, C. L. (2016). Metalloprotein crystallography: more than a structure. Acc. Chem. Res. 49, 695-702. doi: 10. 1021/acs.accounts.5b00538

Bronstein, P. A., Marrichi, M., Cartinhour, S., Schneider, D. J., and DeLisa, M. P. (2005). Identification of a twin-arginine translocation system in Pseudomonas syringae pv. tomato DC3000 and its contribution to pathogenicity and fitness. J. Bacteriol. 187, 8450-8461. doi: 10.1128/JB.187.24.8450-8461. 2005

Cangelosi, G. A., Ankenbauer, R. G., and Nester, E. W. (1990). Sugars induce the Agrobacterium virulence genes through a periplasmic binding protein and a transmembrane signal protein. Proc. Natl. Acad. Sci. U.S.A. 87, 6708-6712. doi: 10.1073/pnas.87.17.6708

Chandra, B. R., Yogavel, M., and Sharma, A. (2007). Structural analysis of ABCfamily periplasmic zinc binding protein provides new insights into mechanism of ligand uptake and release. J. Mol. Biol. 367, 970-982. doi: 10.1016/j.jmb.2007. 01.041

Chandrangsu, P., Rensing, C., and Helmann, J. D. (2017). Metal homeostasis and resistance in bacteria. Nat. Rev. Microbiol. 15, 338-350. doi: 10.1038/nrmicro. 2017.15

Chen, C., Song, Y., Zhuang, K., Li, L., Xia, Y., and Shen, Z. (2015). Proteomic analysis of copper-binding proteins in excess copper-stressed roots of two rice (Oryza sativa L.) varieties with different Cu tolerances. PLoS One 10:e0125367. doi: 10.1371 /journal.pone. 0125367
Christianson, D. W., and Fierke, C. A. (1996). Carbonic anhydrase: evolution of the zinc binding site by nature and by design. Acc. Chem. Res. 29, 331-339. doi: 10.1021/ar9501232

Citovsky, V., De Vos, G., Zambryski, P., Crrovsky, V., and Zambryse, P. (1988). Single-stranded DNA binding protein encoded by the virE locus of Agrobacterium tumefaciens. Science 240, 501-504. doi: 10.1126/science.240. 4851.501

Cobessi, D., Celia, H., Folschweiller, N., Schalk, I. J., Abdallah, M. A., and Pattus, F. (2005). The crystal structure of the pyoverdine outer membrane receptor FpvA from Pseudomonas aeruginosa at $3.6 \AA$ resolution. J. Mol. Biol. 347, 121-134. doi: 10.1016/j.jmb.2005.01.021

Cobine, P. A., Pierrel, F., and Winge, D. R. (2006). Copper trafficking to the mitochondrion and assembly of copper metalloenzymes. Biochim. Biophys. Acta 1763, 759-772. doi: 10.1016/j.bbamcr.2006.03.002

Cornelis, P., Wei, Q., Andrews, S. C., and Vinckx, T. (2011). Iron homeostasis and management of oxidative stress response in bacteria. Metallomics 3, 540-549. doi: $10.1039 / \mathrm{clm} 00022 \mathrm{e}$

Cotton, F. A. (2000). A millennial overview of transition metal chemistry. J. Chem. Soc. Dalton Trans. 1961-1968. doi: 10.1039/b001668n

DeLano, W. L. (2002). The PyMOL Molecular Graphics System. Palo Alto, CA: DeLano Scientific.

Dupont, C. L., Butcher, A., Valas, R. E., Bourne, P. E., and Caetano-Anolles, G. (2010). History of biological metal utilization inferred through phylogenomic analysis of protein structures. Proc. Natl. Aca. Sci. U.S.A. 107, 10567-10572. doi: 10.1073/pnas.0912491107

Elkins, J. M., Ryle, M. J., Clifton, I. J., Dunning Hotopp, J. C., Lloyd, J. S., Burzlaff, N. I., et al. (2002). X-ray crystal structure of Escherichia coli taurine/ $\alpha$-ketoglutarate dioxygenase complexed to ferrous iron and substrates. Biochemistry 41, 5185-5192. doi: 10.1021/bi016014e

Emsley, P., and Cowtan, K. (2004). Coot: model-building tools for molecular graphics. Acta Crystallogr. D Biol. Crystallogr. 60, 2126-2132. doi: 10.1107/ S0907444904019158

Fatima, U., and Senthil-Kumar, M. (2015). Plant and pathogen nutrient acquisition strategies. Front. Plant Sci. 6:750. doi: 10.3389/fpls.2015.00750

Festa, R. A., and Thiele, D. J. (2012). Copper at the front line of the host-pathogen battle. PLoS Pathog. 8:e1002887. doi: 10.1371/journal.ppat.1002887

Finn, R. D., Coggill, P., Eberhardt, R. Y., Eddy, S. R., Mistry, J., Mitchell, A. L., et al. (2016). The Pfam protein families database: towards a more sustainable future. Nucleic Acids Res. 44, D279-D285. doi: 10.1093/nar/gkv1344

Fones, H., and Preston, G. M. (2012). Reactive oxygen and oxidative stress tolerance in plant pathogenic Pseudomonas. FEMS Microbiol. Lett. 327, 1-8. doi: 10.1111/j.1574-6968.2011.02449.x

Fones, H., and Preston, G. M. (2013). The impact of transition metals on bacterial plant disease. FEMS Microbiol. Rev. 37, 495-519. doi: 10.1111/1574-6976.12004

Gao, R., Mack, T. R., and Stock, A. M. (2007). Bacterial response regulators: versatile regulatory strategies from common domains. Trends Biochem. Sci. 32, 225-234. doi: 10.1016/j.tibs.2007.03.002

Ghazaei, C. (2016). Bacterial lipoproteins diverse role in host-pathogen interactions. Res. Rev. BioSci. 11, 1-11.

Grabowska, M., Jagielska, E., Czapinska, H., Bochtler, M., and Sabala, I. (2015). High resolution structure of an M23 peptidase with a substrate analogue. Sci. Rep. 5:14833. doi: 10.1038/srep14833

Hall, T. A. (1999). BioEdit: a user-friendly biological sequence alignment editor and analysis program for Windows 95/98/NT. Nucleic Acids Symp. Ser. 41, 95-98.

Handali, M., Neupane, D. P., Roychowdhury, H., and Yukl, E. T. (2015). Transcriptional regulation, metal binding properties and structure of Pden1597, an unusual zinc transport protein from Paracoccus denitrificans. J. Biol. Chem. 290, 11878-11889. doi: 10.1074/jbc.M115.645853

Hernick, M., and Fierke, C. (2013). "Mechanisms of metal-dependent hydrolases in metabolism," in Comprehensive Natural Products II : Chemistry and Biology, Vol. 8, eds L. Mander, and H. W. Liu , 547-581.

Holland, D. R., Hausrath, A. C., Juers, D., and Matthews, B. W. (1995). Structural analysis of zinc substitutions in the active site of thermolysin. Protein Sci. 4, 1955-1965. doi: 10.1002/pro.5560041001

Hood, M. I., and Skaar, E. P. (2012). Nutritional immunity: transition metals at the pathogen-host interface. Nat. Rev. Microbiol. 10, 525-537. doi: 10.1038/ nrmicro2836 
Huang, D. W., Sherman, B. T., Tan, Q., Collins, J. R., Alvord, W. G., Roayaei, J., et al. (2007). The DAVID Gene Functional Classification Tool: A novel biological module-centric algorithm to functionally analyze large gene lists. Genome Biol. 8:R183. doi: 10.1186/gb-2007-8-9-r183

Ichinose, Y., Taguchi, F., and Mukaihara, T. (2013). Pathogenicity and virulence factors of Pseudomonas syringae. J. General Plant Pathol. 79, 285-296. doi: 10.1007/s10327-013-0452-8

Jones, P., Binns, D., Chang, H. Y., Fraser, M., Li, W., McAnulla, C., et al. (2014). InterProScan 5: genome-scale protein function classification. Bioinformatics 30, 1236-1240. doi: 10.1093/bioinformatics/btu031

Kaim, W., and Rall, J. (1996). Copper-A “Modern" Bioelement. Angew. Chem. Int. Ed. Engl. 35, 43-60. doi: 10.1002/anie.199600431

Kavanagh, K. L., Jörnvall, H., Persson, B., and Oppermann, U. (2008). Mediumand short-chain dehydrogenase/reductase gene and protein families: the SDR superfamily: Functional and structural diversity within a family of metabolic and regulatory enzymes. Cell. Mol. Life Sci. 65, 3895-3906. doi: 10.1007/s00018008-8588-y

Kelley, L. A., Mezulis, S., Yates, C. M., Wass, M. N., and Sternberg, M. J. E. (2015). The Phyre 2 web portal for protein modeling, prediction and analysis. Nat. Protoc. 10, 845-858. doi: 10.1038/nprot.2015.053

Kim, B.-E., Nevitt, T., and Thiele, D. J. (2008). Mechanisms for copper acquisition, distribution and regulation. Nat. Chem. Biol. 4, 176-185. doi: 10.1038/ nchembio.72

Kim, B. J., Park, J. H., Park, T. H., Bronstein, P. A., Schneider, D. J., Cartinhour, S. W., et al. (2009). Effect of iron concentration on the growth rate of Pseudomonas syringae and the expression of virulence factors in hrp-inducing minimal medium. Appl. Environ. Microbiol. 75, 2720-2726. doi: 10.1128/AEM. 02738-08

Kirchberg, J., Büttner, D., Thiemer, B., and Sawers, R. G. (2012). Aconitase b is required for optimal growth of Xanthomonas campestris pv. vesicatoria in pepper plants. PLoS One 7:e34941. doi: 10.1371/journal.pone.0034941

Kong, J., Jiang, H., Li, B., Zhao, W., Li, Z., and Zhu, S. (2016). Complete genome sequence of Pseudomonas syringae pv. lapsa strain ATCC 10859. Isolated from infected wheat. Genome Announc. 4:e00024-16. doi: 10.1128/genomeA. 00024-16

Krewulak, K. D., and Vogel, H. J. (2008). Structural biology of bacterial iron uptake. Biochim. Biophys. Acta 1778, 1781-1804. doi: 10.1016/j.bbamem.2007.07.026

Krogh, A., Larsson, B., von Heijne, G., and Sonnhammer, E. L. (2001). Predicting transmembrane protein topology with a hidden Markov model: application to complete genomes. J. Mol. Biol. 305, 567-580. doi: 10.1006/jmbi.2000.4315

Kyostio, S. R. M., Cramer, C. L., and Lacy, G. H. (1991). Erwinia carotovora subsp. carotovora extracellular protease: characterization and nucleotide sequence of the gene. J. Bacteriol. 173, 6537-6546. doi: 10.1128/jb.173.20.6537-6547.1991

Laskowski, R. A., and Swindells, M. B. (2011). LigPlot+: multiple ligand-protein interaction diagrams for drug discovery. J. Chem. Inf. Model. 1, 2778-2786. doi: $10.1021 / \mathrm{ci} 200227 \mathrm{u}$

Li, X., Zhong, Y., and Zhao, C. (2018). Trypsin binding with copper ions scavenges superoxide: molecular dynamics-based mechanism investigation. Int. J. Environ. Res. Public Health 15:139. doi: 10.3390/ijerph15010139

Lionetto, M. G., Caricato, R., Giordano, M. E., and Schettino, T. (2016). The complex relationship between metals and carbonic anhydrase: new insights and perspectives. Int. J. Mol. Sci. 17:E127. doi: 10.3390/ijms17010127

Liu, T., Song, T., Zhang, X., Yuan, H., Su, L., Li, W., et al. (2014). Unconventionally secreted effectors of two filamentous pathogens target plant salicylate biosynthesis. Nat. Commun. 5:4686. doi: 10.1038/ncomms5686

Lohmeyer, E., Schröder, S., Pawlik, G., Trasnea, P.-I., Peters, A., Daldal, F., et al. (2012). The ScoI homologue SenC is a copper binding protein that interacts directly with the $\mathrm{cbb}_{3}$-type cytochrome oxidase in Rhodobacter capsulatus. Biochim. Biophys. Acta 1817, 2005-2015. doi: 10.1016/j.bbabio.2012.06.621

Lothian, A., Hare, D. J., Grimm, R., Ryan, T. M., Masters, C. L., and Roberts, B. R. (2013). Metalloproteomics: principles, challenges, and applications to neurodegeneration. Front. Aging Neurosci. 5:35. doi: 10.3389/fnagi.2013.00035

Lu, C. H., Lin, Y. F., Lin, J. J., and Yu, C. S. (2012). Prediction of metal ion-binding sites in proteins using the fragment transformation method. PLoS One 7:e39252. doi: 10.1371/journal.pone.0039252

Lubec, G., and Afjehi-Sadat, L. (2007). Limitations and pitfalls in protein identifications by mass spectrometry. Chem. Rev. 107, 3568-3584. doi: 10.1021/ cr068213f
Ludwig, B. (1987). Cytochrome c oxidase in prokaryotes. FEMS Microbiol. Lett. 46, 41-56. doi: 10.1016/0378-1097(87)90185-6

Ma, L., Terwilliger, A., and Maresso, A. W. (2015). Iron and zinc exploitation during bacterial pathogenesis. Metallomics 7, 1541-1554. doi: 10.1039/ C5MT00170F

Mallick, M., Sharan, A., and Shankaracharya, V. (2011). Tools for predicting metal binding sites in protein: a review. Curr. Bioinformatics 6, 444-449. doi: 10.2174/ 157489311798072990

Marchler-Bauer, A., Derbyshire, M. K., Gonzales, N. R., Lu, S., Chitsaz, F., Geer, L. Y., et al. (2015). CDD: NCBI's conserved domain database. Nucleic Acids Res. 43, D222-D226. doi: 10.1093/nar/gku1221

Maret, W. (2013). Zinc biochemistry: from a single zinc enzyme to a key element of life. Adv. Nutr. 4, 82-91. doi: 10.3945/an.112.003038

Marienhagen, J., Kennerknecht, N., Sahm, H., and Eggeling, L. (2005). Functional analysis of all aminotransferase proteins inferred from the genome sequence of Corynebacterium glutamicum. J. Bacteriol. 187, 7639-7646. doi: 10.1128/JB.187. 22.7639-7646.2005

Miller, C. D., Pettee, B., Zhang, C., Pabst, M., McLean, J. E., and Anderson, A. J. (2009). Copper and cadmium: Responses in Pseudomonas putida KT2440. Lett. Appl. Microbiol. 49, 775-783. doi: 10.1111/j.1472-765X.2009.02741.x

Muesch, A., Hartmann, E., Rohde, K., Rubartelli, A., Sitia, R., and Rapoport, T. A. (1990). A novel pathway for secretory proteins? Trends Biochem. Sci. 15, 86-88. doi: 10.1049/em:19950108

Murakami, M., and Hirano, T. (2008). Intracellular zinc homeostasis and zinc signaling. Cancer Sci. 99, 1515-1522. doi: 10.1111/j.1349-7006.2008.00854.x

Nettles, W. L., Song, H., Farquhar, E. R., Fitzkee, N. C., and Emerson, J. P. (2015). Characterization of the copper(II) binding sites in human carbonic anhydrase II. Inorg. Chem. 54, 5671-5680. doi: 10.1021/acs.inorgchem.5b00057

Petersen, T. N., Brunak, S., Von Heijne, G., and Nielsen, H. (2011). SignalP 4.0: discriminating signal peptides from transmembrane regions. Nat. Methods 8 , 785-786. doi: 10.1038/nmeth.1701

Pordea, A. (2015). Metal-binding promiscuity in artificial metalloenzyme design. Curr. Opin. Chem. Biol. 25, 124-132. doi: 10.1016/j.cbpa.2014.12.035

Schreiber, G., and Keating, A. E. (2011). Protein binding specificity versus promiscuity. Curr. Opin. Struct. Biol. 21, 50-61. doi: 10.1016/j.sbi.2010.10.002

Seib, K. L., Jennings, M. P., and McEwan, A. G. (2003). A Sco homologue plays a role in defence against oxidative stress in pathogenic Neisseria. FEBS Lett. 546, 411-415. doi: 10.1016/S0014-5793(03)00632-X

Shannon, P., Markiel, A., Ozier, O., Baliga, N. S., Wang, J. T., Ramage, D., et al. (2003). Cytoscape: a software environment for integrated models of biomolecular interaction networks. Genome Res. 13, 2498-2504. doi: 10.1101/ gr.1239303

Sharma, A., Sharma, D., and Verma, S. K. (2017). Proteome wide identification of iron binding proteins of Xanthomonas translucens pv. undulosa: focus on secretory virulent proteins. BioMetals 30, 127-147. doi: 10.1007/s10534-0179991-3

Shen, H. B., and Chou, K. C. (2010). Gneg-mPLoc: a top-down strategy to enhance the quality of predicting subcellular localization of Gram-negative bacterial proteins. J. Theor. Biol. 264, 326-333. doi: 10.1016/j.jtbi.2010.01.018

Shi, W., and Chance, M. R. (2011). Metalloproteomics: forward and reverse approaches in metalloprotein structural and functional characterization. Curr. Opin. Chem. Biol. 15, 144-148. doi: 10.1016/j.cbpa.2010.11.004

Shi, W., Punta, M., Bohon, J., Sauder, J. M., D’Mello, R., Sullivan, M., et al. (2011). Characterization of metalloproteins by high-throughput X-ray absorption spectroscopy. Genome Res. 21, 898-907. doi: 10.1101/gr. 115097.110

Shi, Y., Wang, Q., Hou, Y., Hong, Y., Han, X., Yi, J., et al. (2014). Molecular cloning, expression and enzymatic characterization of glutathione S-transferase from Antarctic sea-ice bacteria Pseudoalteromonas sp. ANT506. Microbiol. Res. 169, 179-184. doi: 10.1016/j.micres.2013.06.012

Shouldice, S. R., Skene, R. J., Dougan, D. R., Snell, G., McRee, D. E., Schryvers, A. B., et al. (2004). Structural basis for iron binding and release by a novel class of periplasmic iron-binding proteins found in gram-negative pathogens. J. Bacteriol. 186, 3903-3910. doi: 10.1128/JB.186.12.3903-3910.2004

Sitthisak, S., Howieson, K., Amezola, C., and Jayaswal, R. K. (2005). Characterization of a multicopper oxidase gene from Staphylococcus aureus. Appl. Environ. Microbiol. 71, 5650-5653. doi: 10.1128/AEM.71.9.5650-5653. 2005 
Swingle, B., Thete, D., Moll, M., Myers, C. R., Schneider, D. J., and Cartinhour, S. (2008). Characterization of the PvdS-regulated promoter motif in Pseudomonas syringae pv. tomato DC3000 reveals regulon members and insights regarding PvdS function in other pseudomonads. Mol. Microbiol. 68, 871-889. doi: 10. 1111/j.1365-2958.2008.06209.x

Taguchi, F., Suzuki, T., Inagaki, Y., Toyoda, K., Shiraishi, T., and Ichinose, Y. (2010). The siderophore pyoverdine of Pseudomonas syringae pv. tabaci 6605 is an intrinsic virulence factor in host tobacco infection. J. Bacteriol. 192, 117-126. doi: 10.1128/JB.00689-09

Tai, S. S., Yu, C., and Lee, J. K. (2003). A solute binding protein of Streptococcus pneumoniae iron transport. FEMS Microbiol. Lett. 220, 303-308. doi: 10.1016/ S0378-1097(03)00135-6

Tam, R., and Saier, M. H. (1993). Structural, functional, and evolutionary relationships among extracellular solute-binding receptors of bacteria. Microbiol. Rev. 57, 320-346.

Tamura, K., Stecher, G., Peterson, D., Filipski, A., and Kumar, S. (2013). MEGA6: Molecular evolutionary genetics analysis version 6.0. Mol. Biol. Evol. 30, 2725-2729. doi: 10.1093/molbev/mst197

Tanaka, K. J., Song, S., Mason, K., and Pinkett, H. W. (2017). Selective substrate uptake: the role of ATP-binding cassette (ABC) importers in pathogenesis. Biochim. Biophys. Acta 1860, 868-877. doi: 10.1016/j.bbamem.2017.08.011

Tang, S.-S., Lin, C.-C., and Chang, G.-G. (1996). Metal-catalyzed oxidation and cleavage of octopus glutathione transferase by the $\mathrm{Cu}$ (II)-ascorbate system. Free Radic. Biol. Med. 21, 955-964. doi: 10.1016/S0891-5849(96)00230-4

Tavares, P., Pereira, A. S., Moura, J. J. G., and Moura, I. (2006). Metalloenzymes of the denitrification pathway. J. Inorg. Biochem. 100, 2087-2100. doi: 10.1016/j. jinorgbio.2006.09.003

Tripathi, L. P., and Sowdhamini, R. (2008). Genome-wide survey of prokaryotic serine proteases: analysis of distribution and domain architectures of five serine protease families in prokaryotes. BMC Genomics 9:549. doi: 10.1186/14712164-9-549

Tusnady, G. E., and Simon, I. (2001). The HMMTOP transmembrane topology prediction server. Bioinformatics 17, 849-850. doi: 10.1093/bioinformatics/17. 9.849

Valencia-Botín, A. J., and Cisneros-Opez, M. E. (2012). A review of the studies and interactions of Pseudomonas syringae pathovars on wheat. Int. J. Agron. 2012:692350. doi: 10.1155/2012/692350

Vanni, A., Anfossi, L., Pessione, E., and Giovannoli, C. (2002). Catalytic and spectroscopic characterisation of a copper-substituted alcohol dehydrogenase from yeast. Int. J. Biol. Macromol. 30, 41-45. doi: 10.1016/S0141-8130(01) 00188-X

Verma, S. K., Kumar, S., Sheikh, I., Malik, S., Mathpal, P., Chugh, V., et al. (2016a). Transfer of useful variability of high grain iron and zinc from Aegilops kotschyi into wheat through seed irradiation approach. Int. J. Radiat. Biol. 92, 132-139. doi: 10.3109/09553002.2016.1135263

Verma, S. K., Kumar, S., Sheikh, I., Sharma, P., Mathpal, P., Malik, S., et al. (2016b). Induced homoeologous pairing for transfer of useful variability for high grain Fe and $\mathrm{Zn}$ from Aegilops kotschyi into wheat. Plant Mol. Biol. Rep. 34, 1083-1094. doi: 10.1007/s11105-016-0989-8
Verma, S. K., Sharma, A., Sandhu, P., Choudhary, N., Sharma, S., Acharya, V., et al. (2017). Proteome scale identification, classification and structural analysis of iron-binding proteins in bread wheat. J. Inorg. Biochem. 170, 63-74. doi: 10.1016/j.jinorgbio.2017.02.012

Yamamoto, Y., Pargade, V., Lamberet, G., Gaudu, P., Thomas, F., Texereau, J., et al. (2006). The Group B Streptococcus NADH oxidase Nox-2 is involved in fatty acid biosynthesis during aerobic growth and contributes to virulence. Mol. Microbiol. 62, 772-785. doi: 10.1111/j.1365-2958.2006. 05406.x

Yamashita, M. M., Wesson, L., Eisenman, G., and Eisenberg, D. (1990). Where metal ions bind in proteins. Proc. Natl. Acad. Sci. U.S.A. 87, 5648-5652. doi: $10.1073 /$ pnas.87.15.5648

Young, J. M. (2010). Taxonomy of Pseudomonas syringae. J. Plant Pathol. 92, S1.5-S1.14.

Yu, C.-S., Lin, C.-J., and Hwang, J.-K. (2004). Predicting subcellular localization of proteins for Gram-negative bacteria by support vector machines based on n-peptide compositions. Protein Sci. 13, 1402-1406. doi: 10.1110/ps.03479604

Yu, N. Y., Wagner, J. R., Laird, M. R., Melli, G., Rey, S., Lo, R., et al. (2010). PSORTb 3.0: Improved protein subcellular localization prediction with refined localization subcategories and predictive capabilities for all prokaryotes. Bioinformatics 26, 1608-1615. doi: 10.1093/bioinformatics/btq249

Zhang, C. (2014). Essential functions of iron-requiring proteins in DNA replication, repair and cell cycle control. Protein Cell 5, 750-760. doi: 10.1007/ s13238-014-0083-7

Zhang, C., Zhang, F., Zhou, P., and Zhang, C. (2016). Functional role of metalloproteins in genome stability. Front. Biol. 11, 119-131. doi: 10.1007/ s11515-016-1392-4

Zhang, H., Gao, S., Lercher, M. J., Hu, S., and Chen, W. H. (2012). EvolView, an online tool for visualizing, annotating and managing phylogenetic trees. Nucleic Acids Res. 40, W569-W572. doi: 10.1093/nar/gks576

Zhang, Y., Bak, D. D., Heid, H., and Geider, K. (1999). Molecular characterization of a protease secreted by Erwinia amylovora. J. Mol. Biol. 289, 1239-1251. doi: 10.1006/jmbi.1999.2846

Zheng, T., Olson, D. G., Murphy, S. J., Shao, X., Tian, L., and Lynd, L. R. (2017). Both $a d h E$ and a separate NADPH dependent alcohol dehydrogenase gene, adhA, are necessary for high ethanol production in Thermoanaerobacterium saccharolyticum. J. Bacteriol. 199:e00542-16. doi: 10.1128/JB.00542-16

Conflict of Interest Statement: The authors declare that the research was conducted in the absence of any commercial or financial relationships that could be construed as a potential conflict of interest.

Copyright (c) 2018 Sharma, Sharma and Verma. This is an open-access article distributed under the terms of the Creative Commons Attribution License (CC BY). The use, distribution or reproduction in other forums is permitted, provided the original author(s) and the copyright owner(s) are credited and that the original publication in this journal is cited, in accordance with accepted academic practice. No use, distribution or reproduction is permitted which does not comply with these terms. 